ARTICLE

Received 16 Feb 2015 | Accepted 27 Jul 2015 | Published 10 Sep 2015

DOI: $10.1038 /$ ncomms 9164

OPEN

\title{
Blood coagulation protein fibrinogen promotes autoimmunity and demyelination via chemokine release and antigen presentation
}

Jae Kyu Ryu1, Mark A. Petersen1,2, Sara G. Murray, Kim M. Baeten¹, Anke Meyer-Franke1, Justin P. Chan',

Eirini Vagena1, Catherine Bedard', Michael R. Machado', Pamela E. Rios Coronado', Thomas Prod'homme ${ }^{3,4}$, Israel F. Charo ${ }^{5}$, Hans Lassmann ${ }^{6}$, Jay L. Degen ${ }^{7}$, Scott S. Zamvil ${ }^{3,4}$ \& Katerina Akassoglou 1,3,4

Autoimmunity and macrophage recruitment into the central nervous system (CNS) are critical determinants of neuroinflammatory diseases. However, the mechanisms that drive immunological responses targeted to the CNS remain largely unknown. Here we show that fibrinogen, a central blood coagulation protein deposited in the CNS after blood-brain barrier disruption, induces encephalitogenic adaptive immune responses and peripheral macrophage recruitment into the CNS leading to demyelination. Fibrinogen stimulates a unique transcriptional signature in $\mathrm{CD}_{11 \mathrm{~b}}{ }^{+}$antigen-presenting cells inducing the recruitment and local CNS activation of myelin antigen-specific Th1 cells. Fibrinogen depletion reduces Th1 cells in the multiple sclerosis model, experimental autoimmune encephalomyelitis. Major histocompatibility complex (MHC) II-dependent antigen presentation, CXCL10- and CCL2mediated recruitment of $\mathrm{T}$ cells and macrophages, respectively, are required for fibrinogeninduced encephalomyelitis. Inhibition of the fibrinogen receptor CD11b/CD18 protects from all immune and neuropathologic effects. Our results show that the final product of the coagulation cascade is a key determinant of CNS autoimmunity.

\footnotetext{
${ }^{1}$ Gladstone Institute of Neurological Disease, University of California, San Francisco, California 94158, USA. ${ }^{2}$ Division of Neonatology, Department of Pediatrics, University of California San Francisco, San Francisco, California 94143, USA. ${ }^{3}$ Department of Neurology, University of California San Francisco, San Francisco, California 94143, USA. ${ }^{4}$ Program in Immunology, University of California San Francisco, San Francisco, California 94143, USA. ${ }^{5}$ Gladstone Institute of Cardiovascular Disease, University of California, San Francisco, California 94158, USA. ${ }^{6}$ Centre for Brain Research, Medical University of Vienna, Vienna A-1090, Austria. ${ }^{7}$ Division of Experimental Hematology, Cincinnati Children's Hospital Research Foundation and University of Cincinnati College of Medicine, Cincinnati, Ohio 45229, USA. Correspondence and requests for materials should be addressed to S.S.Z. (email: zamvil@ucsf.neuroimmunol.org) or K.A. (email: kakassoglou@gladstone.ucsf.edu).
} 
D isruption of the homeostatic balance between the vasculature and the brain is a sustained and often early feature of neurologic diseases and traumatic insults to the central nervous system (CNS). Understanding how blood-brain barrier (BBB) disruption instigates and amplifies immune and degenerative responses leading to brain pathology and loss of function would be instrumental in the design of novel treatments for neurologic diseases. Fibrinogen (coagulation factor I) is a major component in the blood that upon $\mathrm{BBB}$ disruption enters the CNS and is deposited as insoluble fibrin ${ }^{1}$. Although soluble fibrinogen in the bloodstream is not proinflammatory, activation of the coagulation cascade results in the formation of fibrin associated with exposure of cryptic epitopes that transform fibrinogen from a blood factor to a potent activator of innate immunity $^{1}$. In multiple sclerosis (MS) and experimental autoimmune encephalomyelitis (EAE), BBB disruption and fibrin deposition are detected in the white matter along with microglial activation before T-cell infiltration and the onset of demyelination ${ }^{2-6}$. Indeed, increased coagulation activity leading to fibrin formation occurs early in neuroinflammation before demyelination ${ }^{4}$, and is highly upregulated in active MS plaques ${ }^{7}$. Moreover, injection of soluble fibrinogen in the healthy brain results in fibrin formation ${ }^{5}$. Fibrin deposition is abundant not only in early but also active and chronic MS lesions, and correlates with demyelination and T-cell infiltration ${ }^{3,8-10}$. Genetic or pharmacologic depletion of fibrinogen decreases microglial activation and axonal damage and attenuates neurologic signs in $\mathrm{EAE}^{5,7,11-13}$ and other MS models ${ }^{14,15}$. While studies in EAE mice support a role for fibrin in the activation of microglia in myelinated areas, its role in the initiation and propagation of myelin-targeted adaptive immune responses is unknown. Moreover, despite the vast literature on BBB disruption and activation of the coagulation cascade in brain diseases, there is currently no model of neuroinflammation induced by a coagulation factor.

Here we developed a model of coagulation-driven demyelination to directly assess the role of $\mathrm{BBB}$ disruption and fibrin in the induction of CNS autoimmunity and demyelination. Surprisingly, introduction of fibrinogen into the healthy CNS was sufficient to induce activation of adaptive immunity targeted to CNS myelin antigens leading to demyelination. The effect of fibrinogen as an initiator of CNS autoimmunity was first substantiated in vivo, where a single stereotactic injection of fibrinogen in the corpus callosum induced recruitment and local differentiation of myelin antigen-specific Th1 cells leading to demyelination. In accordance, endogenous fibrinogen was required for T-helper 1 (Th1) cell activation in EAE. Microarray analysis in cell autonomous systems of antigen-presenting cells (APCs) uncovered a unique transcriptional signature for fibrin that links the coagulation cascade with M1-type activation of APCs associated with induction of antigen presentation and release of leukocyte recruiting chemokines. Rescue experiments to genetically deplete the fibrin-specific immune responses in APCs demonstrated that secretion of the monocyte chemoattractant protein-1 (MCP-1/ CCL2) and the C-X-C motif ligand-10 (CXCL10), together with MHC II-dependent antigen presentation, are essential molecular mediators for fibrin-induced autoimmune responses in the CNS. Furthermore, we showed that fibrin induces CNS autoimmune responses not via its prohaemostatic functions, but due to CD11b/CD18 receptor activation in APCs. Our results show for the first time that a component of the coagulation cascade induces autoimmunity, attributes the CNS effects of coagulation to the proinflammatory effects of fibrin and introduces fibrinogeninduced encephalomyelitis (FIE) as a novel coagulation-driven, autoimmune-mediated model for the study of novel mechanisms and therapies for brain inflammation.

\section{Results}

Fibrinogen in the CNS induces inflammatory demyelination. To determine whether fibrinogen extravasation is sufficient to induce CNS pathology in vivo, we stereotactically injected fibrinogen at its physiological plasma concentration into the corpus callosum, the largest CNS white matter tract associated with disability in $\mathrm{MS}^{16}$. Surprisingly, this single injection of fibrinogen spontaneously induced local demyelination within 7 days (Fig. 1a). Microglial activation was rapidly induced 1 day after fibrinogen injection and preceded demyelination (Fig. 1a). Activation of innate immunity regulates autoimmune responses including $\mathrm{T}$-cell recruitment and differentiation ${ }^{17,18}$. Fibrinogen injection induced infiltration of both $\mathrm{CD} 4^{+}$and $\mathrm{CD} 8{ }^{+} \mathrm{T}$-cell populations in the CNS, but not in the spleen (Fig. 1a,b; Supplementary Fig. 1). T-cell infiltration occurred as early as 1 day after injection and markedly increased 3 and 7 days after injection (Fig. 1a), thus also preceding demyelination. Injection of fibrinogen in the spinal cord ventral column also induced inflammatory demyelination (Supplementary Fig. 2). Neuropathologic alterations were not observed after injection of control artificial cerebrospinal fluid (ACSF) in either the brain or spinal cord (Fig. 1; Supplementary Fig. 2). Although microglia show a diffuse response in the cortex along the needle track 1 day after ACSF injection, this response resolves and no alterations are observed either in the cortex or the corpus callosum (Fig. 1). While wild-type (WT) plasma induced demyelination similar to fibrinogen, injection of plasma from fibrinogen-deficient $\left(\mathrm{Fib}^{-/-}\right)$mice $^{19}$, which contains all plasma proteins except fibrinogen, led to an $82 \%$ reduction in demyelination compared with WT plasma (Supplementary Fig. 3). Injection of the plasma proteins albumin or high-molecular-weight kininogen had no effect (Supplementary Fig. 3).

Activation of the coagulation cascade converts fibrinogen to proinflammatory fibrin primarily due to exposure of a cryptic epitope in the fibrinogen $\gamma$ chain $\left(\gamma_{377-395}\right)$, which binds to $\mathrm{CD} 11 \mathrm{~b} / \mathrm{CD} 18$ integrin (Mac-1, complement receptor 3, $\left.\alpha_{M} \beta_{2}\right)^{20,21}$. The interaction of fibrin with CD11b/CD18 is genetically targeted in Fib $\gamma^{390-396 A}$ mice, in which fibrinogen has been mutated to lack the CD11b/CD18-binding motif, but retains normal clotting function ${ }^{22}$. Injection of plasma derived from Fib $\gamma^{390-396 A}$ mice resulted in a $70 \%$ reduction in demyelination compared with WT plasma (Supplementary Fig. 3), suggesting that the interaction of fibrin with CD11b/ CD18 is required for the induction of demyelination. Since a portion of fibrinogen in the plasma is known to bind extracellular matrix proteins and growth factors, we also produced and tested recombinant fibrinogen, which is clottable and hydrodynamically indistinguishable from plasma fibrinogen, with the exception that it did not carry other plasma-derived factors $^{23}$. Similar to plasma fibrinogen, recombinant fibrinogen also induced demyelination and microglial activation (Supplementary Fig. 4). These results suggest that fibrinogen is a major component in the plasma that in the healthy CNS white matter triggers T-cell recruitment and demyelination even in the absence of pre-existing inflammatory or myelin abnormalities.

Fibrinogen induces M1-type activation of APCs. Genome-wide microarray analysis either in the corpus callosum after fibrinogen injection or in cell autonomous systems of fibrin-stimulated microglia or bone marrow-derived macrophages (BMDMs) revealed a unique fibrin transcriptional signature enriched in genes regulating immune responses, particularly those required to induce activation of T cells by $\mathrm{APCs}^{24}$, such as $\mathrm{MHC}$ II, CD86 and $I L-12$, and recruitment of $\mathrm{T}$ cells and peripheral macrophage into the $\mathrm{CNS}^{25-27}$, such as CXCL10 and CCL2 
a

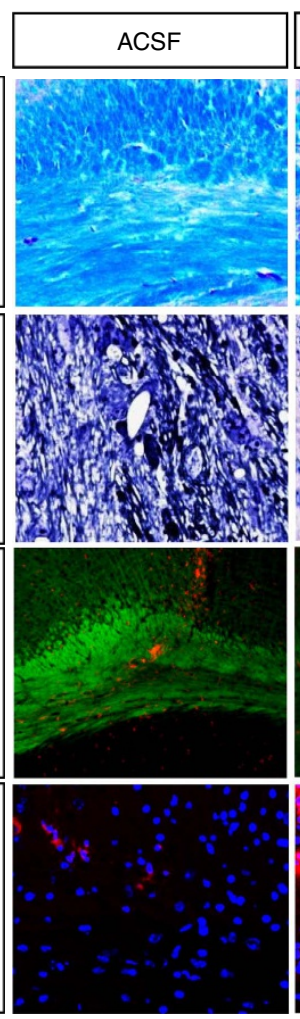

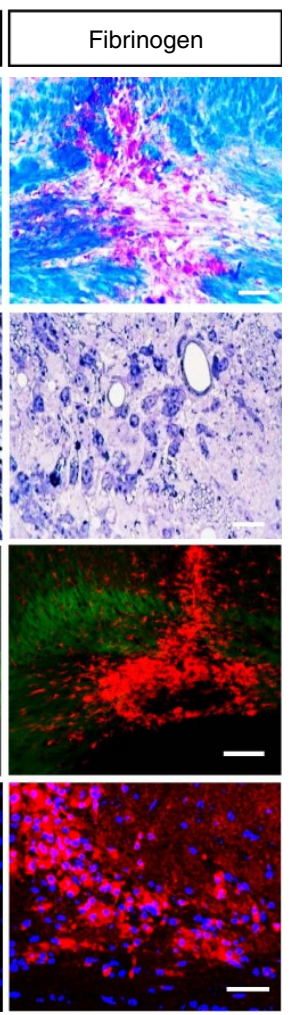
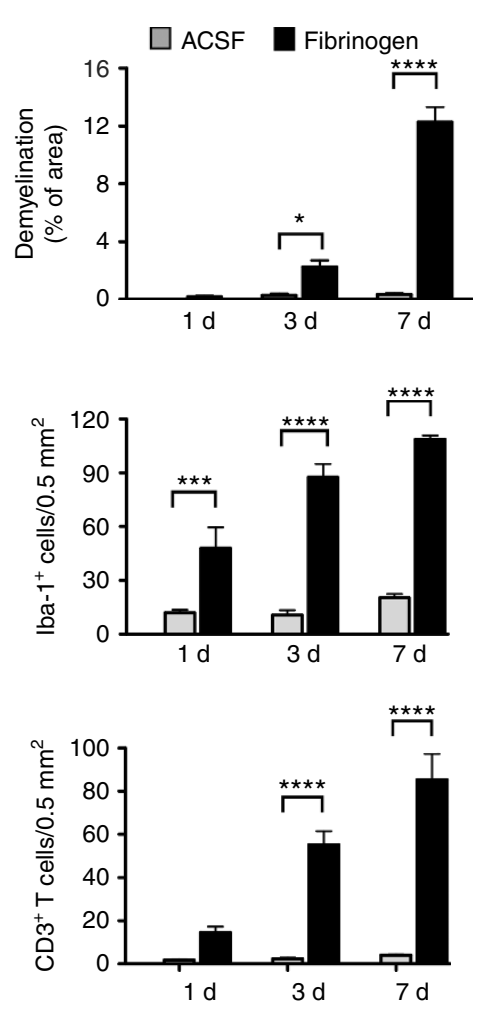

b
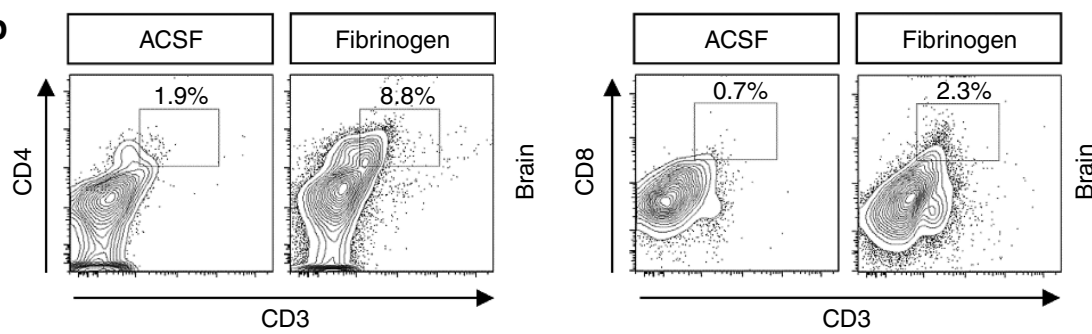

Figure 1 | Induction of T-cell recruitment and inflammatory demyelination by a single fibrinogen injection in the CNS. (a) Demyelination (LFB/PAS and toluidine blue), microglial activation and demyelination (MBP/Iba-1), and T-cell infiltration (CD3) in the corpus callosum of mice injected with fibrinogen compared with ACSF control. Scale bar, $100 \mu \mathrm{m}$ (top panel); $10 \mu \mathrm{m}$ (second panel); $100 \mu \mathrm{m}$ (third panel); $80 \mu \mathrm{m}$ (bottom panel). Representative histological sections from day 7 after injection are shown. Data are presented as mean \pm s.e.m. $\left(n=5-6\right.$ mice per time point). ${ }^{\star} P<0.05,{ }^{\star \star \star} P<0.001,{ }^{\star \star \star \star} P<0.0001$ (two-way ANOVA and Bonferroni's multiple comparisons test). (b) FACS analysis of T cells isolated from the brain (corpus callosum) 7 days after fibrinogen or ACSF injection stained with CD3, CD4 and CD8 ( $n=3$ independent experiments; each experiment generated from pooled brain cells from $n=3-4$ mice). ANOVA, analysis of variance; d, days; FACS, fluorescence-activated cell sorting; LFB, Luxol fast blue.

(Fig. 2a-d; Supplementary Tables 1-3). Other immune response genes, such as complement components, lipocalin and proteins involved in iron binding and oxidative stress, were also increased. Fibrin induced M1-type activation and induction of antigenpresenting genes in both primary microglia and BMDMs (Fig. 2c; Supplementary Fig. 5). Consistent with these findings, protein and gene expression of MHC class II and CD86 were also induced in fibrin-exposed BMDMs, and were inhibited by anti-CD11b treatment (Fig. 2d; Supplementary Fig. 6). Lipopolysaccharide (LPS) was used as a positive control (Fig. 2d; Supplementary Fig. 6). In agreement, fibrinogen injection in the corpus callosum induced MHC class II and CXCL10 in $\mathrm{Iba}^{+}{ }^{+}$cells (Supplementary Fig. 7a,b). Similar to fibrinogen, injection of WT plasma in the corpus callosum induced CXCL10 expression, while plasma derived from $\mathrm{Fib}^{-1}$ or Fib $\gamma^{390-396 A}$ mice showed a significant reduction (Supplementary Fig. 7c). Strikingly, $M H C$

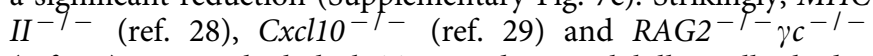
(ref. 30) mice, which lack T, B and natural killer cells, had a marked reduction in demyelination after fibrinogen injection compared with WT mice (Fig. 2e). Cxcl10 $-1-$ mice also had 54\% less T-cell infiltration than WT mice after fibrinogen injection (Supplementary Fig. 8). Overall, these results suggest that fibrin is a potent activator of APCs that triggers demyelination via T-cell recruitment into the CNS.

Fibrinogen promotes recruitment of encephalitogenic $\mathrm{T}$ cells. To examine whether fibrinogen could induce $\mathrm{T}$-cell responses against myelin antigens in vivo, we tested its effects in $2 \mathrm{D} 2$ transgenic mice constitutively expressing T-cell antigen receptors (TCRs) specific for myelin oligodendrocyte glycoprotein $(\mathrm{MOG})^{31}$. After fibrinogen injection in the corpus callosum, T-cell infiltration and demyelination in 2D2 mice were $46 \%$ and $51 \%$ higher, respectively, compared with WT mice (Fig. 3a). In contrast, in control OT-II transgenic mice constitutively expressing TCRs specific for ovalbumin (OVA), an antigen not present in the $\mathrm{CNS}^{32}$, T-cell infiltration after fibrinogen injection was $77 \%$ and $66 \%$ less than in $2 \mathrm{D} 2$ or WT mice, respectively (Fig. 3a). Consistent with this result, demyelination was also 
a

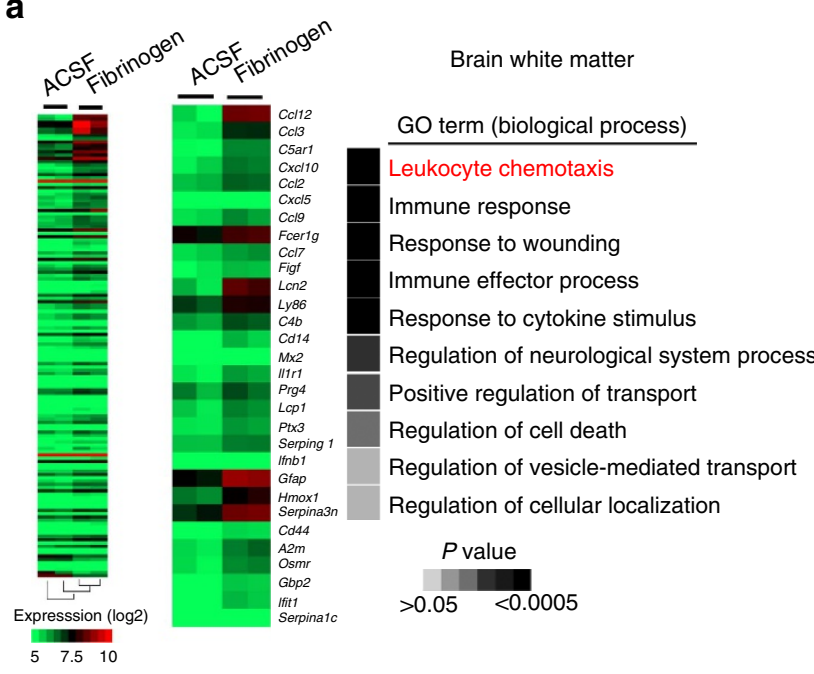

b

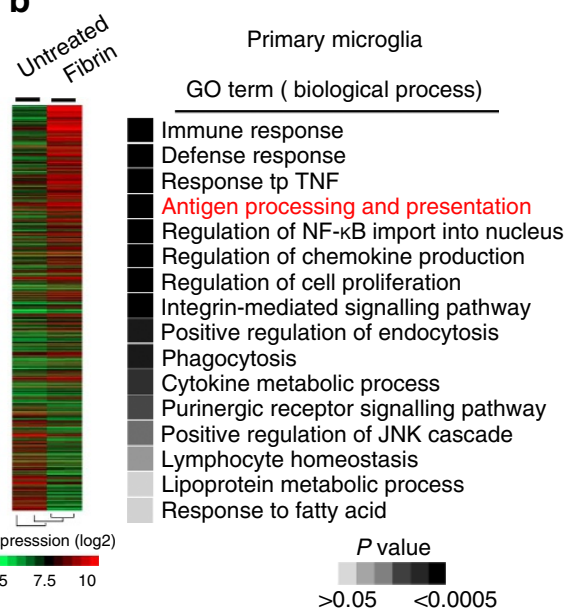

c

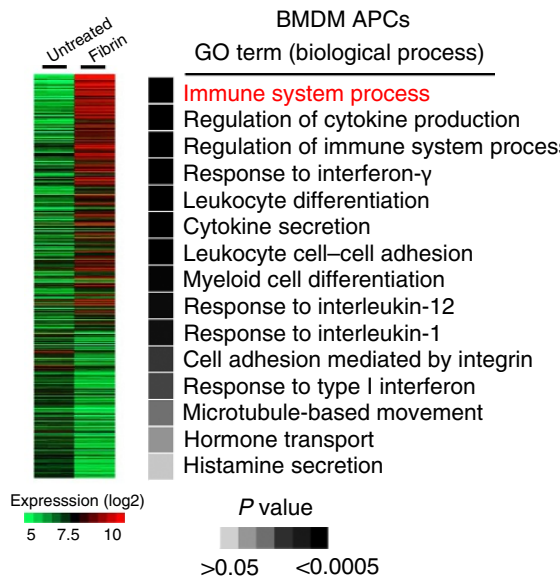

d

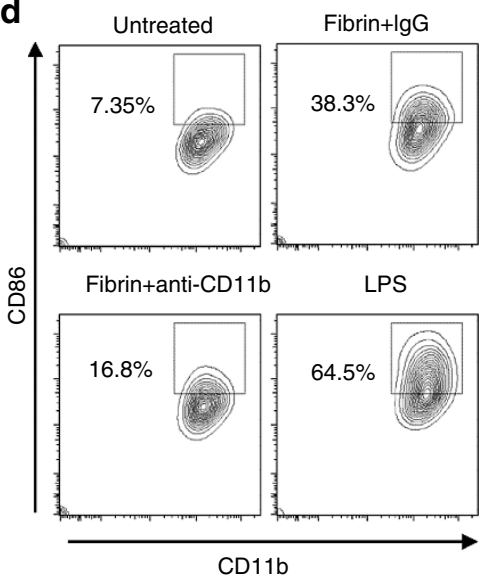

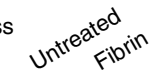

APCs: M1 genes

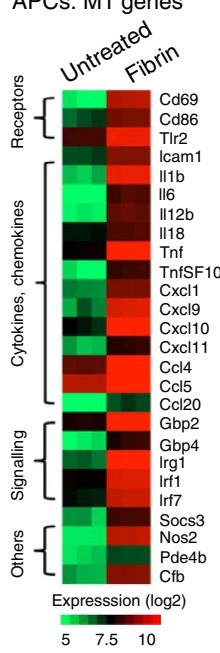

e

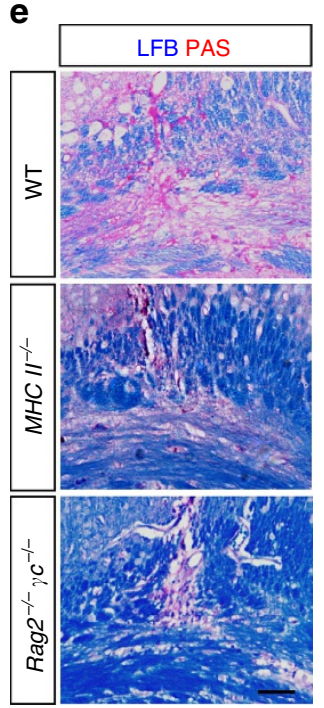

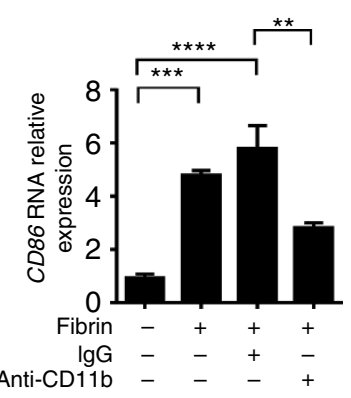

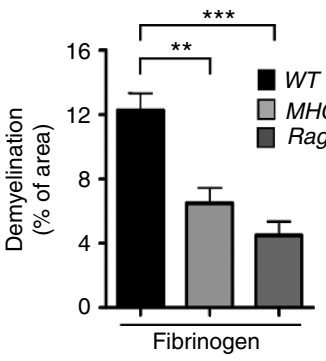

Anti-CD11b $-\quad-\quad++$

Figure 2 | Adaptive immunity and antigen presentation are required for fibrinogen-induced demyelination. (a) Affymetrix microarray gene expression analysis and enrichment of gene ontology (GO) of fibrinogen-injected or ACSF-injected corpus callosum at $12 \mathrm{~h}$ post injection. Heatmaps of the 142 genes with $\geq 1.5 \times$ change in expression between ACSF and fibrinogen. (b) Affymetrix microarray gene expression analysis of fibrin-stimulated rat primary microglia at $6 \mathrm{~h}$ in vitro. Heatmap and GO analysis of gene expression profiles of 1,342 genes with $\geq 1.5 \times$ change in expression between unstimulated and fibrin treatment. (c) Affymetrix microarray gene expression analysis of fibrin-stimulated mouse APCs at $6 \mathrm{~h}$ in vitro. Heatmap and GO analysis of gene expression profiles of key genes with $\geq 1.5 \times$ change in expression (left). Heatmap of the M1-related genes with $\geq 2.0 \times$ change in expression after fibrin stimulation (right). (d) FACS analysis of CD86 expression in APCs after fibrin stimulation. LPS was used as positive control. Anti-CD11b antibody treatment reduces CD86 expression in APCs. Real-time PCR analysis of CD86 gene expression in BMDMs after fibrin stimulation treated with anti-CD11b or IgG isotype control antibody. Data are presented as mean \pm s.e.m. ( $n=4$ independent experiments; right). ${ }^{\star \star} P<0.01$, ${ }^{\star \star \star} P<0.001,{ }^{\star \star \star \star} P<0.0001$ (one-way ANOVA). (e) Demyelination (LFB/PAS) in the corpus callosum of WT, MHC $I^{-/-}$or $R A G 2^{-/-} \gamma C^{-/-}$mice 7 days after fibrinogen injection. Representative images are shown. Scale bar, $100 \mu \mathrm{m}$. Data are presented as mean \pm s.e.m. ( $n=6$ mice per group). ${ }^{\star \star} P<0.01,{ }^{\star \star \star} P<0.001$ (one-way ANOVA and Bonferroni's multiple comparisons test). ANOVA, analysis of variance; FACS, fluorescence-activated cell sorting; LFB, Luxol fast blue. 
a
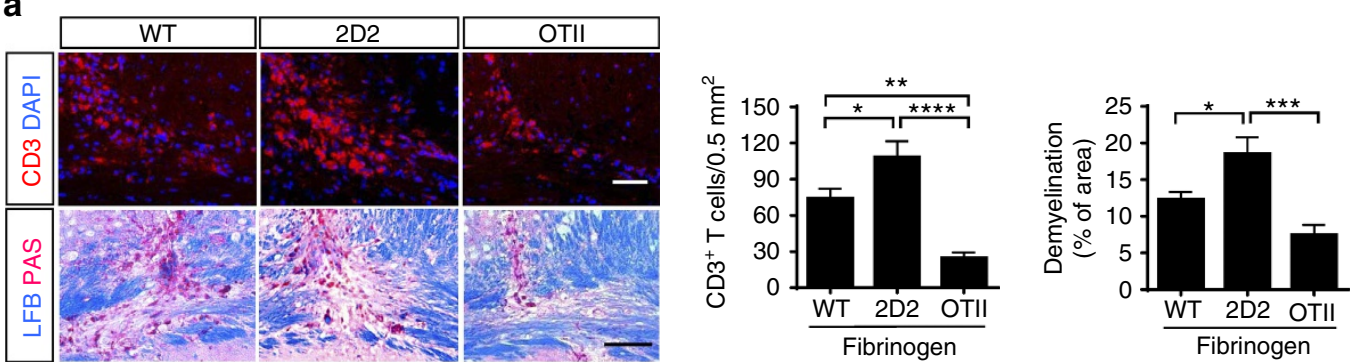

b

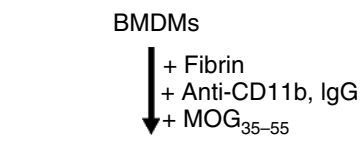

Co-cultured with naive $2 \mathrm{D} 2 \mathrm{CD}^{+} \mathrm{T}$ cells

BrdU assay

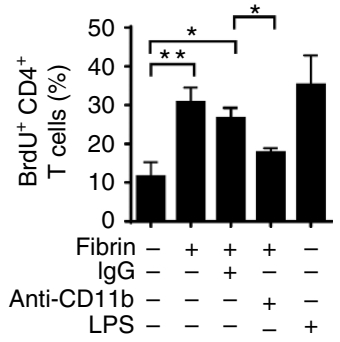

C
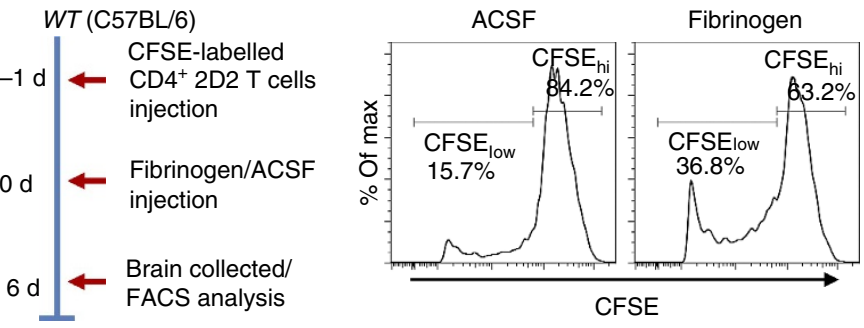

d
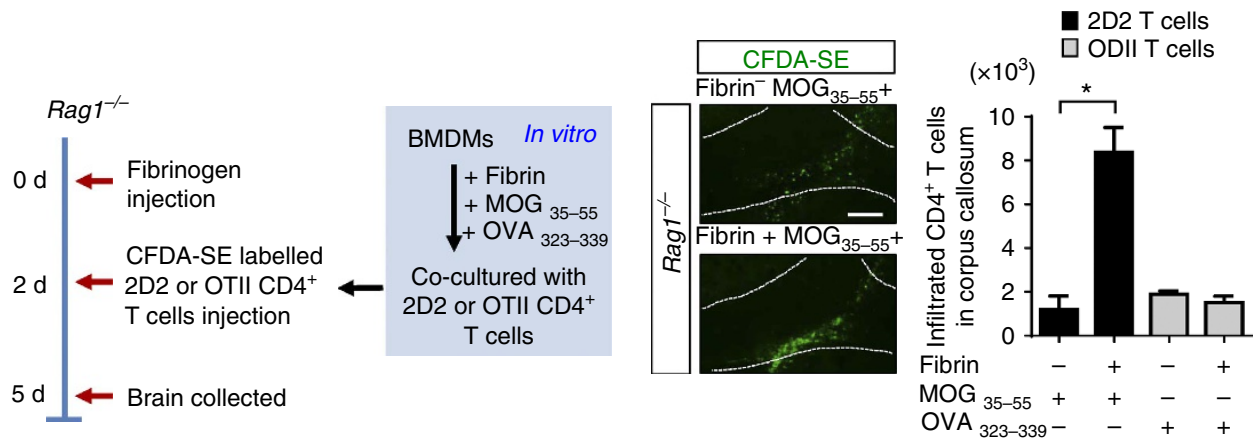

Figure 3 | Extravascular fibrinogen drives myelin-specific T cells into the CNS. (a) T-cell infiltration (CD3) and demyelination (LFB/PAS) in the corpus callosum of WT, 2D2 and OT-II mice 7 days after fibrinogen injection. Scale bars, $100 \mu \mathrm{m}$ (top panel); $200 \mu \mathrm{m}$ (bottom panel). Quantification of CD3 ${ }^{+}$T cells and demyelination at 7 days after fibrinogen injection. Data are presented as mean \pm s.e.m. ( $n=6$ mice per group). ${ }^{\star} P<0.05,{ }^{\star \star} P<0.01,{ }^{\star \star \star} P<0.001$, ${ }^{\star \star \star \star \star} P<0.0001$ by one-way ANOVA and Bonferroni's multiple comparisons test. (b) BMDMs treated with fibrin alone or in the presence of anti-CD11b or

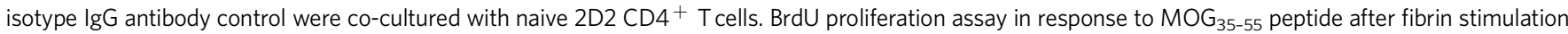
and anti-CD11b treatment. LPS was used as positive control. Data are presented as mean \pm s.e.m. $\left(n=3-4\right.$ independent experiments, ${ }^{\star} P<0.05$, ${ }^{\star \star} P<0.01$ by one-way ANOVA and Bonferroni's multiple comparisons test). (c) WT recipient mice received CFSE-labelled CD4 ${ }^{+} \mathrm{CD} 62 \mathrm{~L}+2 \mathrm{D} 2 \mathrm{~T}$ cells $(0 \mathrm{~d})$ and 1 day later fibrinogen or ACSF were injected in the corpus callosum. CFSE-labelled 2D2 T cells were isolated from the brains of fibrinogen- or ACSF-injected mice 6 days later and analysed by FACS. FACS plots and quantification showing CFSE dilution (CFSE low $_{\text {) }}$ ) indicate proliferation of 2D2 T cells in fibrinogen-injected brain. Data are representative of two independent experiments, each from pooled brain cells from $n=4$ mice. (d) Naive CD4 ${ }^{+} 2 \mathrm{D} 2$ or control OT-II T cells were co-cultured with BMDMs treated with the indicated peptides, MOG $_{35-55}$ or OVA $323-339$ alone or peptide in the presence of fibrin. CFDA-SE-labelled 2D2 or

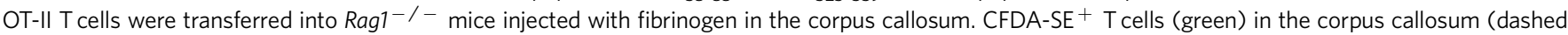
line) of Rag1 ${ }^{-1-}$ mice. Scale bar, $100 \mu \mathrm{m}$. Quantification shows increased 2D2 T cells after co-culture with BMDMs treated with both fibrin and MOG $35-55$ compared with fibrin and $\mathrm{OVA}_{323-339}$ or $\mathrm{MOG}_{35-55}$ alone. Data are presented as mean \pm s.e.m. $\left(n=4\right.$ mice per group, ${ }^{\star} P<0.05$ by non-parametric Mann-Whitney U-test). ANOVA, analysis of variance; d, days; FACS, fluorescence-activated cell sorting; LFB, Luxol fast blue.

significantly reduced in OT-II mice (Fig. 3a). Fibrin-treated BMDMs significantly increased the proliferation of $\mathrm{MOG}_{35-55^{-}}$ treated $\mathrm{CD} 4{ }^{+} 2 \mathrm{D} 2 \mathrm{~T}$ cells in a CD11b-dependent manner, further suggesting that fibrin-induced activation of APCs promotes myelin-specific T-cell activation (Fig. 3b). LPS was used as a positive control (Fig. 3b).
Fibrinogen promotes CNS expansion of encephalitogenic $\mathrm{T}$ cells. In addition to macrophages, microglia contribute to antigen presentation and T-cell activation during CNS autoimmune diseases $^{33}$. This prompted us to investigate whether fibrin-induced microglial activation also influenced the activation of encephalitogenic $\mathrm{T}$ cells. Co-culture of microglia with naive 2D2 
$\mathrm{T}$ cells in the presence of MOG peptide increased antigen-specific cell proliferation (Supplementary Fig. 9). Importantly, fibrinstimulated microglia were more efficient APC for encephalitogenic T-cell proliferation than unstimulated microglia (Supplementary Fig. 9). On the basis of these findings, we asked whether fibrin induced activation of encephalitogenic $\mathrm{T}$ cells in the CNS. We labelled naive MOG-specific 2D2 T cells with carboxyfluorescein diacetate succinimidyl ester (CFSE) to monitor lymphocyte proliferation in vivo ${ }^{34,35}$. CFSE-labelled 2D2 T cells were adoptively transferred into fibrinogen- or control ACSFinjected WT mice and donor T cells were reisolated from the brain at 6 days after the transfer (Fig. 3c). MOG-specific 2D2 T cells proliferated in the brains of fibrinogen-injected recipients, compared with ACSF-injected controls (Fig. 3c), suggesting local T-cell activation. We next examined whether fibrin-induced activation of APCs promotes encephalitogenic T-cell trafficking into the CNS. Naive 2D2 or control OT-II $T$ cells were co-cultured with BMDMs in the presence of $\mathrm{MOG}_{35-55}$ or $\mathrm{OVA}_{323-339}$, respectively. We adoptively transferred stimulated 2D2 or OT-II T cells into Rag1 ${ }^{-1-}$ recipients that had been injected with fibrinogen and assessed migrated $\mathrm{T}$ cells in the corpus callosum after 3 days. Accumulation of $2 \mathrm{D} 2$ $\mathrm{T}$ cells in the corpus callosum was observed when donor $2 \mathrm{D} 2 \mathrm{~T}$ cells were stimulated with their cognate antigen in the presence of fibrin-treated BMDMs, compared with only

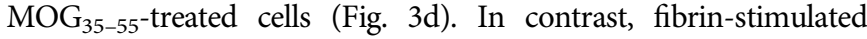
BMDMs did not promote the accumulation of OT-II T cells in the corpus callosum of $R a g 1^{-1-}$ recipients that had been injected with fibrinogen (Fig. 3d). These results suggest that fibrin signalling via $\mathrm{CD} 11 \mathrm{~b} / \mathrm{CD} 18$ primes APCs, which facilitates the local expansion of antigen-specific encephalitogenic $\mathrm{T}$ cells within the CNS.

Fibrinogen activates endogenous myelin antigen-specific $\mathrm{T}$ cells. Local CNS activation of antigen-specific $\mathrm{T}$ cells in the brain drives autoimmune reactions ${ }^{18,36}$. Using the $I-A^{b} M^{b} G_{35-55}$ tetramer to detect in situ myelin-specific $\mathrm{CD} 4^{+} \mathrm{T}$ cells $^{37,38}$, we examined whether fibrinogen entry in the CNS induces the local activation of myelin antigen-specific T cells. After 7 days post injection, isolated lymphocytes from draining lymph nodes were cultured with $\mathrm{MOG}_{35-55}$ peptide (Fig. 4a). Ex vivo staining with $\mathrm{MOG}_{35-55}$ tetramer of cells from draining lymph nodes showed a small but detectable fraction of tetramerpositive CD4 T cells only in fibrinogen-injected, but not in ACSFinjected mice. No tetramer-positive cells were detected on incubation with control $\mathrm{I}^{\mathrm{A}} \mathrm{A}^{\mathrm{b}} \mathrm{OVA}_{323-339}$ tetramer (Fig. 4b), suggesting that fibrinogen induced myelin antigen-specific T-cell activation. Interestingly, only $\mathrm{CD} 4{ }^{+} \mathrm{T}$ cells isolated from the cervical lymph nodes of fibrinogen-injected, but not ACSF-injected mice showed increased bromodeoxyuridine (BrdU) incorporation on $\mathrm{MOG}_{35-55}$ stimulation (Fig. 4c). To examine T-cell responses in the SJL/J mouse strain, lymphocytes were isolated from draining lymph nodes of fibrinogen-injected SJL/J mice and cultured with different proteolipid protein (PLP) peptides, including $\mathrm{PLP}_{139-151}$ and $\mathrm{PLP}_{178-191}$, which are immunodominant epitopes in the SJL/J mouse strain. CD4 ${ }^{+}$T cells of fibrinogen-injected SJL/ $\mathrm{J}$ mice did not show significant proliferation in response to $\mathrm{PLP}_{139-}$ 151 or to ACSF (Supplementary Fig. 10), suggesting that perhaps isolation and expansion of a higher number of $\mathrm{T}$ cells from the draining lymph node and the CNS would be required to study responses to other myelin antigens after induction of FIE in other strains. In our study, $\mathrm{MOG}_{35-55}$ tetramer binding (Fig. $4 \mathrm{~b}$ ) and $\mathrm{MOG}_{35-55}$-induced BrdU incorporation (Fig. 4c) demonstrate the presence of functional autoreactive myelin antigen-specific $\mathrm{CD}^{+} \mathrm{T}$ cells in mice with fibrinogen-induced inflammatory demyelination.
Fibrin induces Th1-cell differentiation via CD11b/CD18. T-cell differentiation into either Th1 or Th17 cells is central to the induction of autoimmune demyelination, and is pertinent to MS pathogenesis ${ }^{39,40}$. In a co-culture system of $\mathrm{CD} 4{ }^{+} \mathrm{T}$ cells with BMDMs stimulated with a fibrin preparation, we observed elevated expression of Th1 (T-bet), but not Th2 (Gata-3) or Th17 (Rorc) transcription factors (Fig. 5a). In accordance, the frequency of interferon- $\gamma(\mathrm{IFN}-\gamma){ }^{+} \mathrm{CD} 4{ }^{+} \mathrm{T}$ cells, but not interleukin (IL)- $4^{+} \mathrm{CD} 4{ }^{+} \mathrm{T}$ cells, was higher when co-cultured with fibrin-stimulated BMDMs (Fig. 5b). Treatment of fibrinstimulated BMDMs with an antibody against CD11b (M1/70) reduced the frequency of IFN- $\gamma^{+} \mathrm{CD} 4^{+} \mathrm{T}$ cells and the gene expression of IFN- $\gamma$ compared with treatment with isotype control antibody (Fig. 5b). Fibrin stimulation of BMDMs increased expression of the Th1-promoting cytokine IL-12p40 (ref. 41), which was markedly blocked by anti-CD11b treatment (Fig. 5b). Co-culture of BMDMs stimulated with kininogen did not induce Th1-cell differentiation (Supplementary Fig. 11). Introduction of fibrinogen in the CNS increased expression of the Th1 transcription factor, T-bet, but not the Th2, Th17 or regulatory T-cell transcription factors, Gata-3, Rorc and FoxP3, respectively (Fig. 5c). In accordance, fibrinogen injection increased gene expression of the Th1 cytokine IFN- $\gamma$ and $I L-12 p 40$, while it had no effect on the expression of $I L-4$ (Th2) and IL-17F (Th17) (Fig. 5c). T cells isolated from the fibrinogeninjected corpus callosum also displayed increased IFN- $\gamma$ expressing cells among infiltrated $\mathrm{CD} 4^{+}$and $\mathrm{CD} 8{ }^{+} \mathrm{T}$ cells by 6.19- and 28.2-fold, respectively (Fig. 5d). In contrast, fibrinogen injection did not significantly increase the number of IL- $4^{+}$or $\mathrm{IL}-17^{+}$in $\mathrm{CD}^{+}{ }^{+}$and $\mathrm{CD} 8{ }^{+} \mathrm{T}$ cells as compared with ACSF injection (Fig. 5d). Fibrinogen induced local Th1 polarization specifically in the brain, as no changes were observed in the spleen (Fig. 5d). In accordance, depletion of fibrinogen in EAE reduced the number and proliferation of IFN- $\gamma^{+} \mathrm{T}$ cells, while no effects were observed in IL-4 ${ }^{+} \mathrm{T}$ cells (Fig. 5e). Overall, these findings introduce the novel concept that a plasma-derived coagulation factor, fibrinogen, may be a key molecular pathway to selectively induce release of Th1-polarizing cytokines in APCs and increase the effector function of encephalitogenic $\mathrm{T}$ cells.

Fibrinogen induces macrophage recruitment into the CNS. Recruitment of $\mathrm{CCR} 2^{+}$peripheral monocytes regulate the severity of demyelination ${ }^{26,42}$, and are essential for EAE progression to paralytic disease ${ }^{43,44}$. We injected fibrinogen into $C c r 2^{R F P /+} C_{x} 3 c r 1^{G F P /+}$ mice, which differentially label resident microglia (green fluorescent protein (GFP) positive $\left(\mathrm{GFP}^{+}\right.$), green) and inflammatory monocytes (red fluorescent protein (RFP) positive $\left(\mathrm{RFP}^{+}\right)$, red $)^{42} \cdot \mathrm{RFP}^{+}$cells were detected at 3 days after injection and their numbers remained elevated at 7 days after injection (Fig. 6a). GFP ${ }^{+}$cells rapidly accumulated 1 day after fibrinogen injection and gradually increased up to 7 days post injection (Fig. 6a), suggesting that microglial activation preceded peripheral macrophage cell infiltration. No $\mathrm{RFP}^{+}$cells were found in the corpus callosum after ACSF injection. These results suggest that in addition to T-cell infiltration, extravascular fibrinogen also triggers recruitment of inflammatory monocytes into the CNS.

Fibrinogen increased $\mathrm{Ccl} 2$ in the corpus callosum in vivo, and after stimulation of primary microglia and APCs (Fig. 2a-c). Interestingly, the local upregulation of CCL2 appeared to be instrumental in FIE. Indeed, peripheral macrophage recruitment, T-cell infiltration and demyelination were reduced following fibrinogen injection into $C$ cr2 $2^{R F P / R F P}$ mice lacking the CCL2 receptor (Fig. 6b). Like purified fibrinogen, WT plasma was a potent inducer of $C c l 2$ and $C x c l 10$ expression, whereas injection of 
a

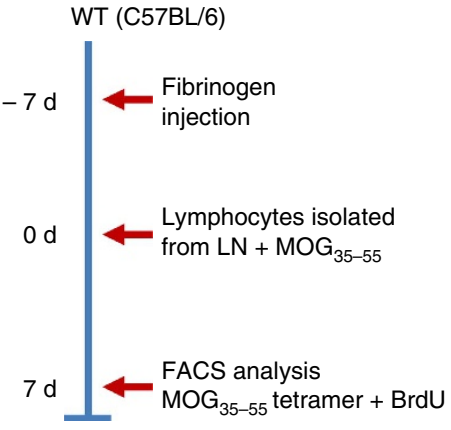

b Cervical lymph nodes
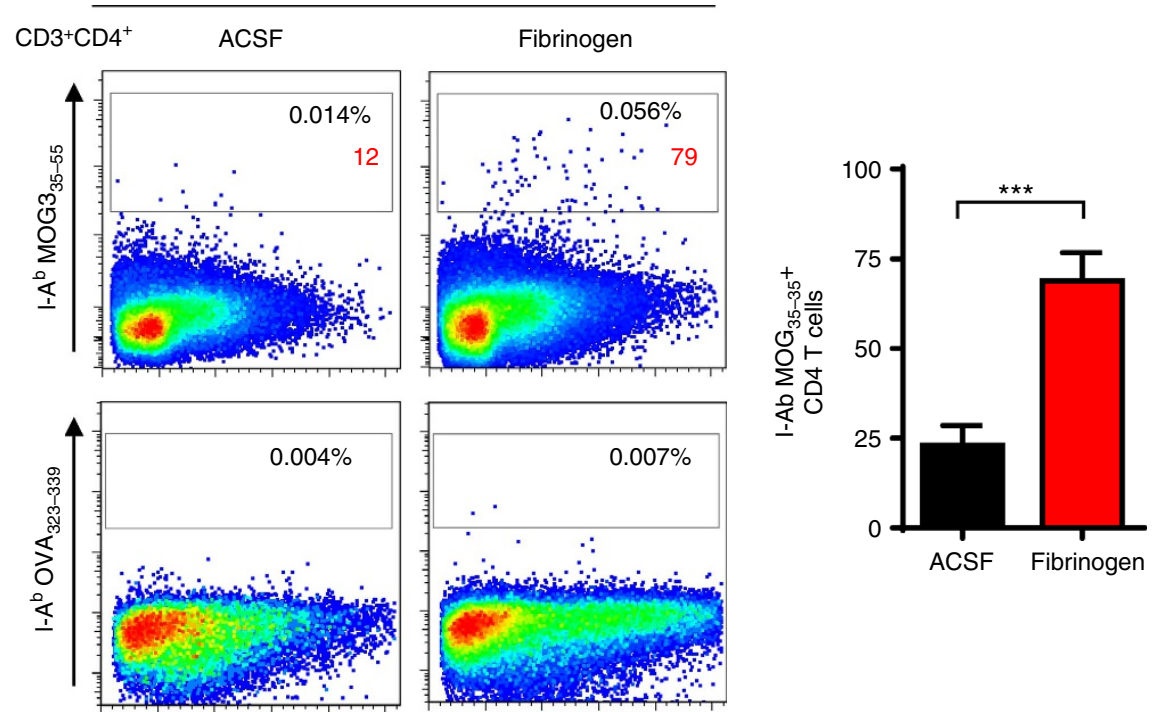

\section{C}

Cervical lymph nodes
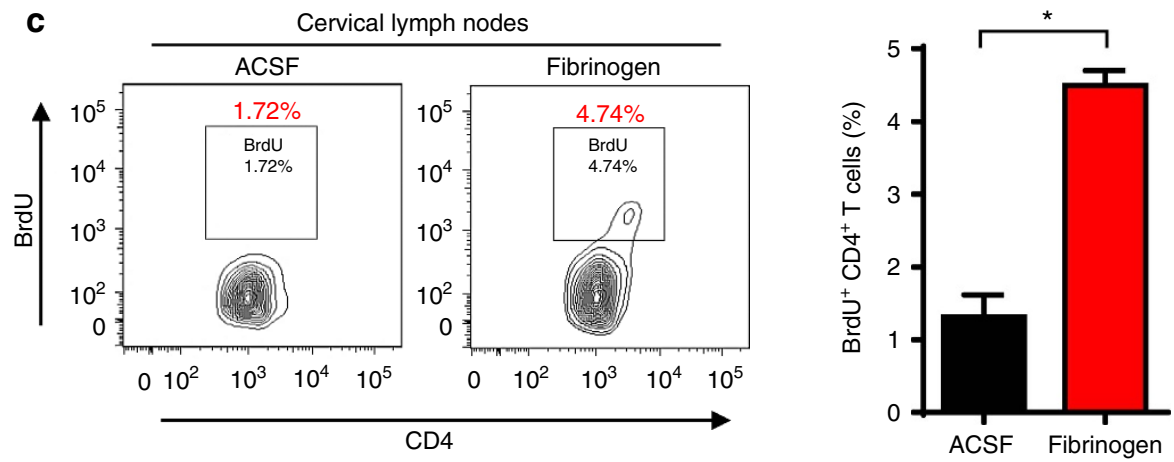

Figure 4 | Fibrinogen drives accumulation of myelin antigen-specific T cells. (a) Experimental design diagram: C57BL/6 mice were stereotaxically injected with fibrinogen or ACSF in the corpus callosum. Seven days after injection, lymphocytes were prepared from draining lymph nodes and stimulated with $\mathrm{MOG}_{35-55}$ for $7 \mathrm{~d}$. I- $\mathrm{A}^{\mathrm{b}} \mathrm{MOG}_{35-55}$ tetramer was used to detect myelin-specific CD4 ${ }^{+}$T cells in fibrinogen-injected WT mice. I-A ${ }^{\mathrm{b}}$ OVA $\mathrm{A}_{323-339}$ tetramer was used as a negative control for $M O_{35-55}$ tetramer staining. (b) Flow cytometry analysis of I-A ${ }^{b} M_{35-55}$ tetramer stained CD4 ${ }^{+}$T cells 7 days after $\mathrm{MOG}_{35-55}$ stimulation. No tetramer-positive cells were detected with I-A ${ }^{\mathrm{b}}$ OVA $\mathrm{A}_{323-339}$ tetramer. Graph shown number of $\mathrm{I}-\mathrm{A}^{\mathrm{b}} \mathrm{MOG}_{35-55}$ tetramer stained CD4 ${ }^{+}$T cells. Data are presented as mean \pm s.e.m., $n=8-9$, with each sample being pooled from 2-3 mice from three independent experiments.

${ }^{\star \star \star} P<0.001$ (non-parametric Mann-Whitney U-test). (c) Proliferation analysis of BrdU incorporation in CD4 ${ }^{+} \mathrm{T}$ cells of ACSF- and fibrinogen-injected mice, stimulated with $\mathrm{MOG}_{35-55}$ for 7 days. Data are presented as mean \pm s.e.m. (four independent experiments with pooled cells from 2-3 mice per experiment for ACSF and fibrinogen), ${ }^{\star} P<0.05$ (non-parametric Mann-Whitney U-test). d, days.

either Fib ${ }^{-1}$ or Fib $\gamma^{390-396 A}$ plasma resulted in their significant reduction (Fig. 6c; Supplementary Fig. 7c). Overall, these results suggest that fibrinogen-induced upregulation of $C c l 2$ via $C D 11 b /$ CD18 facilitates the recruitment of peripheral macrophages and contributes to the induction of inflammatory demyelination.

CD11b inhibition rescues the fibrinogen CNS effects. To further examine whether CD11b/CD18 signalling is required for fibrinogen-induced demyelination, we injected fibrinogen into the corpus callosum of CD11b-deficient mice $\left(\text { Itgam }^{-1-}\right)^{45}$. Microglial activation, T-cell infiltration, demyelination and expression of $\mathrm{Cxcl10}, \mathrm{Ccl} 2, \mathrm{~T}$-bet, IFN- $\gamma$ and $I L-12 p 40$ were significantly decreased in Itgam $^{-1-}$ mice after fibrinogen injection, compared with WT (Fig. 7), suggesting the requirement for $\mathrm{CD} 11 \mathrm{~b} / \mathrm{CD} 18$ signalling in fibrinogen-induced adaptive immune activation. Expression of OX-40, a co- 
a
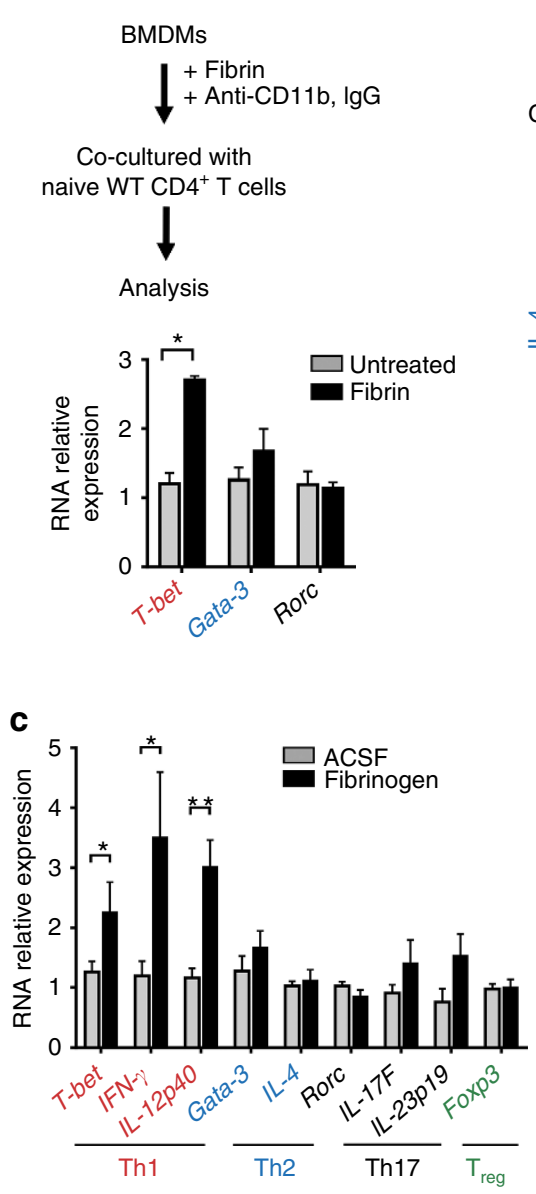

e

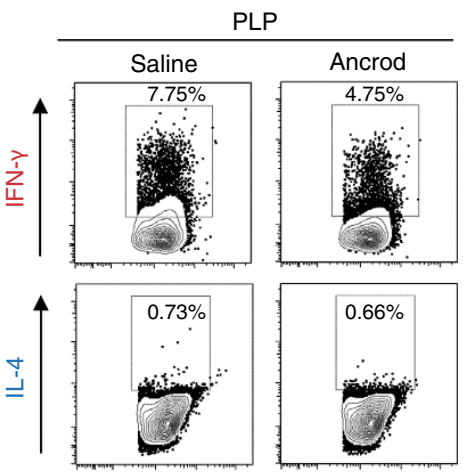

b
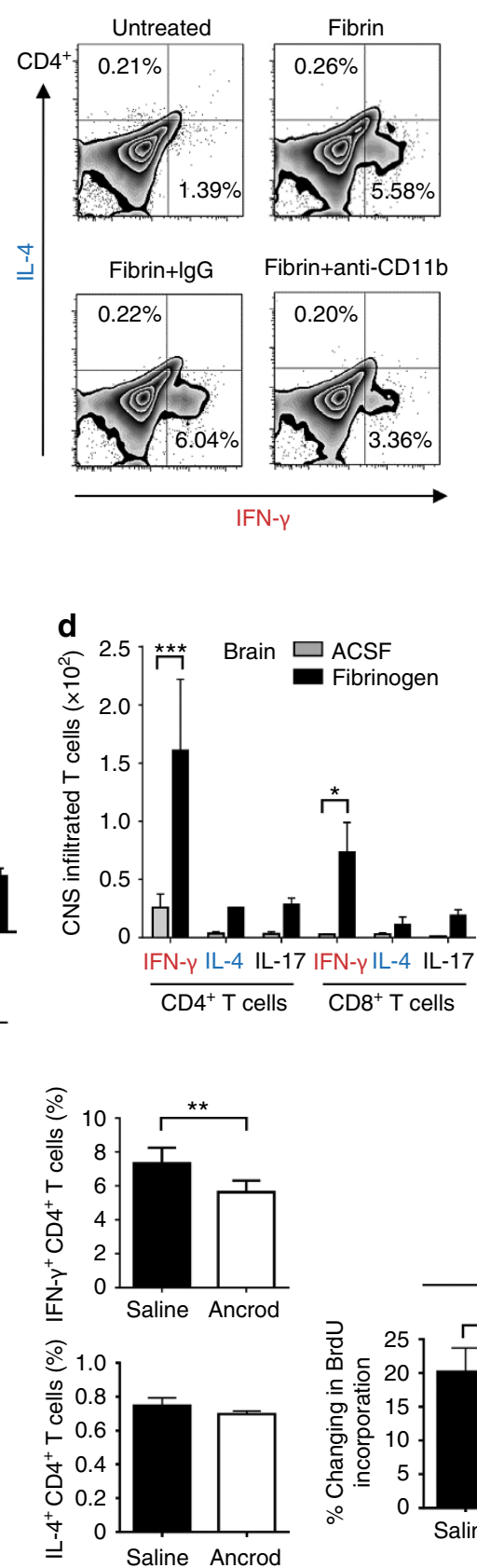
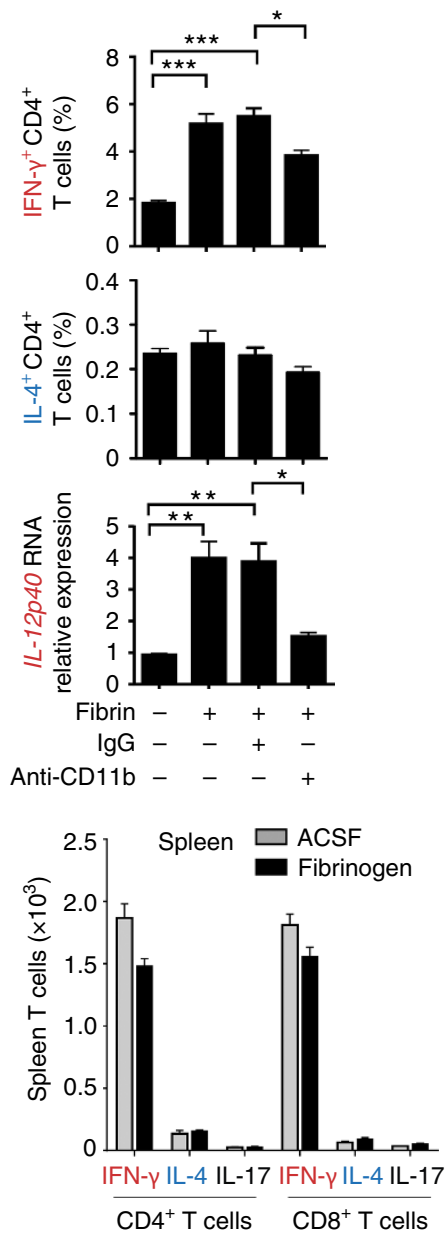

Anti-CD11b - $-\quad+$

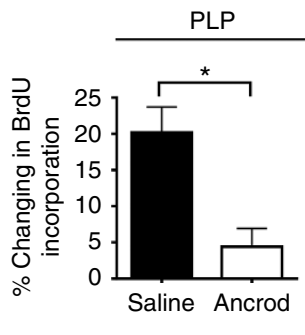

Figure 5 | Fibrin induces activation of innate immunity via CD11b/CD18 to induce Th1-cell differentiation. (a) BMDMs treated with fibrin or in the presence of anti-CD11b or isotype IgG antibody control were co-cultured with naive WT CD4 ${ }^{+}$T cells and analysed for gene expression or by FACS. Gene expression analysis of transcriptional factors indicative of Th1, Th2, Th17 and $\mathrm{T}_{\text {reg }}$ cells in CD4 ${ }^{+}$T cells co-cultured with fibrin-stimulated BMDMs. Data are presented as mean \pm s.e.m. ( $n=4$ independent experiments, ${ }^{\star} P<0.05$ by non-parametric Mann-Whitney $U$-test). (b) Gated percentage of IFN- $\gamma$ - or IL-4-expressing CD4 ${ }^{+}$T cells after co-culture with fibrin-stimulated BMDMs in the presence of rat IgG isotype control antibody or anti-CD11b antibody. Data are presented as mean \pm s.e.m. ( $n=3$ independent experiments, ${ }^{\star} P<0.05,{ }^{\star \star} P<0.01,{ }^{\star \star \star} P<0.001$ by one-way ANOVA and Bonferroni's multiple comparisons test). Real-time PCR analysis of Th1-inducing cytokine IL-12p40 in fibrin-stimulated BMDMs in the presence or absence of anti-CD11b antibody. Data are presented as mean \pm s.e.m. $\left(n=3-4\right.$ independent experiments, ${ }^{\star} P<0.05,{ }^{\star \star} P<0.01$ by one-way ANOVA and Bonferroni's multiple comparisons test). (c) Real-time PCR analysis of transcription factors and cytokines indicative of Th1, Th2, Th17 and Treg cells in the corpus callosum at 3 days after ACSF or fibrinogen injection. Data are presented as mean \pm s.e.m. $\left(n=3-5\right.$ mice per group). ${ }^{\star} P<0.05$ (non-parametric Mann-Whitney U-test). (d) Comparison of IFN- $\gamma$-, IL-4- and IL-17-producing cells in infiltrated CD4 ${ }^{+}$and CD8 ${ }^{+}$T cells isolated from the brains and spleens after ACSF or fibrinogen injection at day 7 post injection. Data are presented as mean \pm s.e.m. $\left(n=3\right.$ independent experiments, ${ }^{\star} P<0.05,{ }^{\star \star \star} P<0.001$ by one-way ANOVA and Bonferroni's multiple comparisons test). (e) IFN- $\gamma$ and IL-4 expression in CD4 ${ }^{+}$lymph node T cells isolated from saline- or fibrin-depleted (ancrod) mice after $\mathrm{PLP}_{139-151}$-induced EAE and restimulated in vitro with $\mathrm{PLP}_{139-151}$. Data are presented as mean \pm s.e.m. $\left(n=6\right.$ mice per group, ${ }^{\star} P<0.05$, ${ }^{\star \star} P<0.01$ by non-parametric Mann-Whitney $U$-test). ANOVA, analysis of variance; FACS, fluorescence-activated cell sorting; $T_{\text {reg, }}$ regulatory $T$ cell. 
a
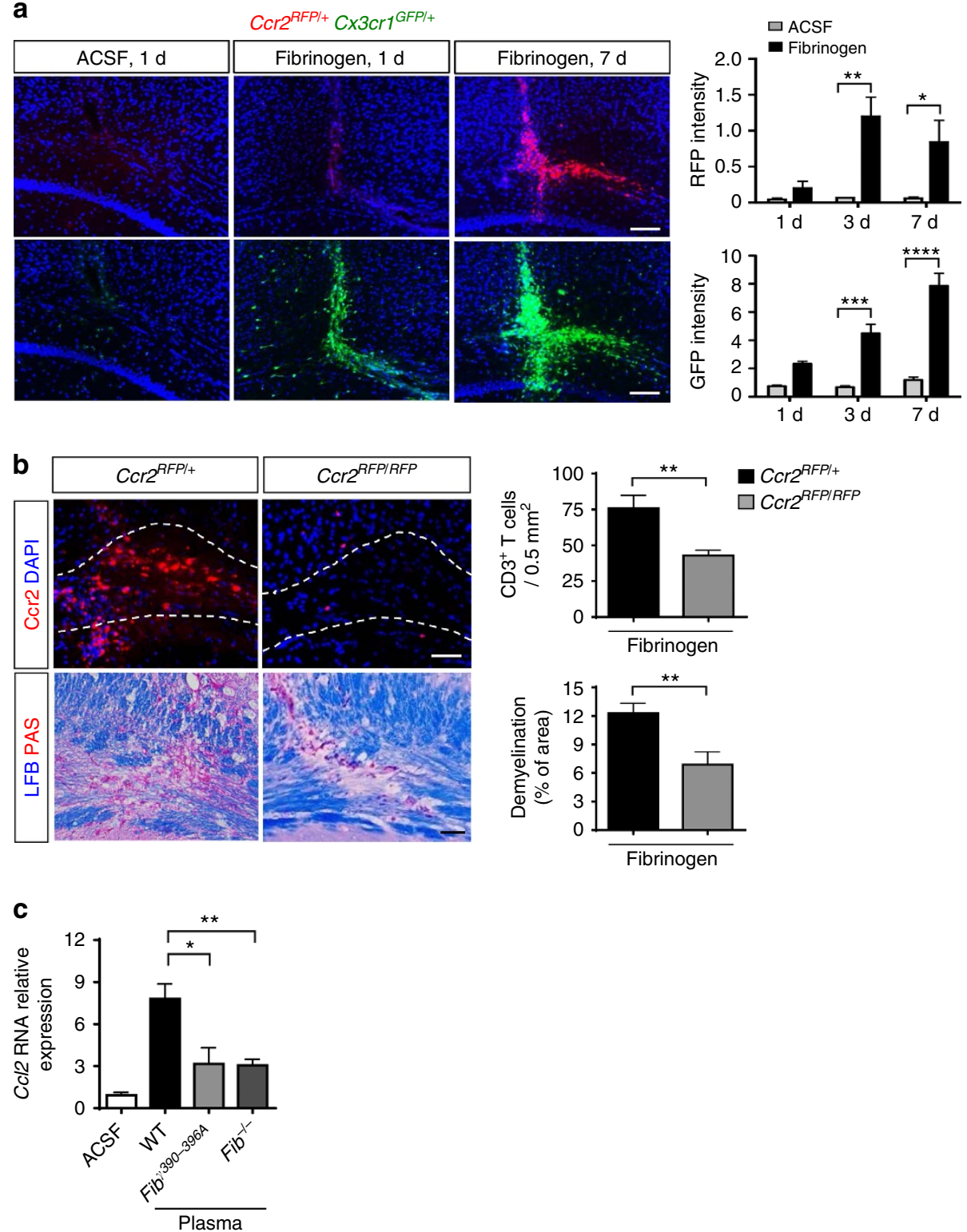

Figure 6 | Fibrinogen induces recruitment of peripheral macrophages into the CNS via CD11b/CD18-mediated upregulation of CCL2. (a) Infiltration of peripheral $\mathrm{Ccr}^{+}$macrophages (RFP, red) in the corpus callosum 7 days after fibrinogen injection in $\mathrm{Ccr} 2^{\text {RFP/ }}+{ } \mathrm{Cx} 3 \mathrm{cr} \mathrm{F}^{\mathrm{GFP} /+}$. Scale bar, $200 \mu \mathrm{m}$. Quantification of RFP (top graph) and GFP (bottom graph) intensity in the same sections of corpus callosum of ACSF- or fibrinogen-injected Ccr2 ${ }^{R F P /}+{ }^{C} \times 3 \mathrm{cr} 1^{G F P /}+{ }_{\text {mice }}$ on days 1, 3 and 7. Data are presented as mean \pm s.e.m. ( $n=4-6$ mice per time point). ${ }^{\star} P<0.05$, ${ }^{\star \star} P<0.01,{ }^{\star \star \star} P<0.001,{ }^{\star \star \star \star} P<0.0001$ (two-way ANOVA and Bonferroni's multiple comparisons test). (b) Infiltration of peripheral $\mathrm{Ccr} 2^{+}$macrophages (RFP, red) in the corpus callosum 7 days after fibrinogen injection in $\mathrm{Ccr} 2^{R F P /+}$ - and Ccr2-deficient ( $\mathrm{Ccr} 2^{\text {RFP/RFP }}$ ) mice at 7 days post-fibrinogen injection. Scale bar, $50 \mu \mathrm{m}$. Quantification of infiltrated $\mathrm{CD} 3{ }^{+} \mathrm{T}$ cells (top graph) and demyelinated area (bottom graph) in the corpus callosum of $C \mathrm{cr} 2^{\text {RFP } /+}$ - and $\mathrm{Ccr} 2$-deficient $\left(C \mathrm{cr} 2^{\text {RFP/RFP }}\right.$ ) mice 7 days after fibrinogen injection. Data are presented as mean \pm s.e.m. ( $n=6-7$ mice per group). ${ }^{\star \star} P<0.01$ (non-parametric Mann-Whitney $U$-test). (c) Real-time PCR analysis of $C c 12$ gene expression in corpus callosum $12 \mathrm{~h}$ after injection of ACSF and plasma obtained from WT, Fib ${ }^{390-396 \mathrm{~A}} \mathrm{Fib}^{-/}$- or mice. Data are presented as mean \pm s.e.m. $(n=4$ mice per group). ${ }^{\star} P<0.05,{ }^{\star \star} P<0.01$ (one-way ANOVA and Bonferroni's multiple comparisons test). ANOVA, analysis of variance; $d$, days.

stimulatory molecule expressed in activated $\mathrm{T}$ cells ${ }^{46}$, increased by $\sim 30$-fold is on CNS-infiltrating $\mathrm{T}$ cells after fibrinogen injection (Fig. 8a). OX-40-labelled T-cell activation was significantly reduced in Itgam $^{-1}$ mice after fibrinogen injection by $\sim 60 \%$ (Fig. $8 \mathrm{a}$ ), suggesting that fibrinogen induces local CNS T-cell activation in a CD11b-dependent manner. Consistent with these results, in mice challenged by fibrinogen injection into the corpus callosum pharmacologic inhibition of CD11b by intracerebroventricular delivery of $\mathrm{M} 1 / 70$ reduced expression of Cxcl10 and Ccl2 (Fig. 8b), and decreased T-cell and peripheral macrophage infiltration (Fig. 8c), when compared with isotype control IgG-treated cohorts. Taken together, these data suggest that the introduction of fibrinogen into CNS tissues induces peripheral immune cell recruitment, T-cell activation and demyelination via a CD11b/CD18-dependent mechanism.

\section{Discussion}

This study establishes the fundamental role of the coagulation cascade as a driver of adaptive immune responses and the mechanisms by which extravasation of a blood clotting factor into the brain white matter can induce autoimmunity, demyelination and peripheral macrophage recruitment into the CNS. Our results 

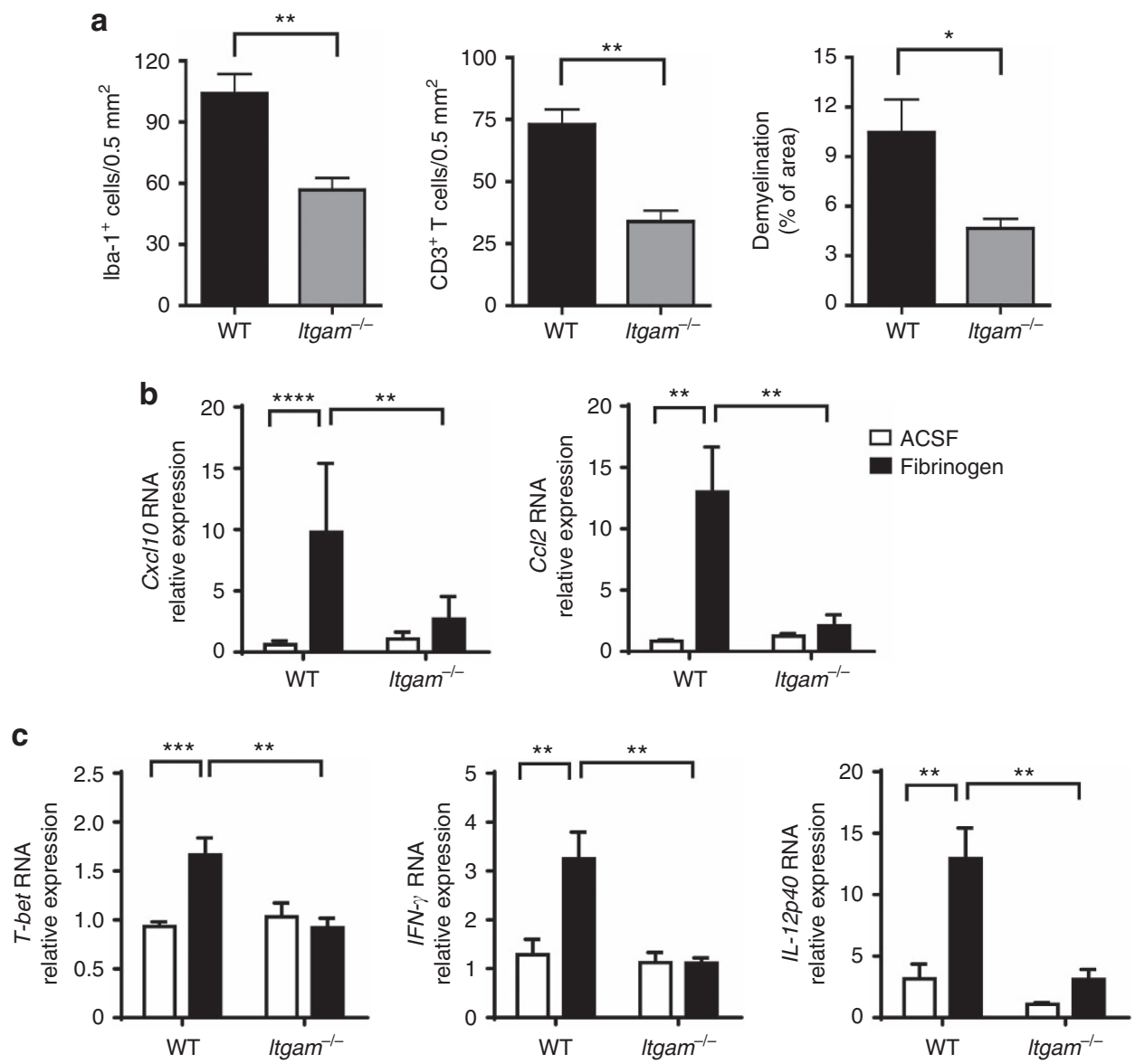

Figure 7 | Genetic inhibition of CD11b blocks fibrinogen-induced microglial activation and inflammatory demyelination. (a) Quantification of microglial activation (IBA-1), T-cell infiltration (CD3) and demyelination (LFB/PAS) 7 days after fibrinogen injection in the corpus callosum of Itgam ${ }^{-/-}$or control WT mice $(n=6)$. Data are presented as mean \pm s.e.m. ${ }^{\star} P<0.05,{ }^{\star \star} P<0.01$ (non-parametric Mann-Whitney $U$-test). (b) Fibrinogen-induced gene expression of $\mathrm{Cxcl} 10$ and $\mathrm{C} / 2$ is reduced in the corpus callosum of Itgam ${ }^{-1-}$ mice compared with WT control. Results are mean \pm s.e.m. of 6-7 mice per group, ${ }^{\star \star} P<0.01,{ }^{\star \star \star \star} P<0.0001$ (two-way ANOVA and Bonferroni's multiple comparisons test). (c) Fibrinogen-induced gene expression of $T$-bet, IFN- $\gamma$ and IL-12p40 is reduced in the corpus callosum of Itgam ${ }^{-1-}$ mice compared with WT control ( $n=5-8$ mice). Data are presented as mean \pm s.e.m. ${ }^{\star \star} P<0.01,{ }^{\star \star \star} P<0.001$ (two-way ANOVA and Bonferroni's multiple comparisons test). ANOVA, analysis of variance; d, days; LFB, Luxol fast blue.

suggest that fibrin, the final product of the coagulation cascade, constitutes a sustained, non-diffusible and geographically constrained immunological molecular switch that triggers the inopportune local activation of resident APCs to induce the proliferation, recruitment and local activation of myelin antigenspecific Th1 cells in the CNS. The introduction of fibrinogen in myelinated areas in the healthy CNS led to the four major findings (Fig. 8d): (i) fibrinogen leakage in the CNS is a major plasma protein that induces CNS autoimmune responses and demyelination; (ii) fibrinogen is a key inducer of recruitment of both encephalitogenic $\mathrm{T}$ cells and peripheral macrophages into the CNS via CXCL10 and CCL2 chemokine secretion, respectively; (iii) activation of the coagulation cascade in the CNS favours Th1-cell differentiation via fibrin-induced upregulation of IL-12; and (iv) the effects of coagulation to CNS autoimmunity are primarily due to the proinflammatory, CD11b-mediated effects of fibrin, thus dissecting the beneficial prohaemostatic roles of coagulation from its damaging effects in CNS disease. Fibrinogen is not only sufficient to induce T-cell activation and demyelination in the healthy CNS, but is also required for T-cell activation after peripheral autoimmune activation as shown on depletion of endogenous fibrinogen in EAE. These new findings, together with our prior studies in EAE showing (i) early activation of coagulation ${ }^{4}$ and (ii) reduction of neurological signs, microglial activation, demyelination and axonal damage on fibrinogen depletion ${ }^{5,11,14}$, bolster the significance of coagulation activity in the development of neuroinflammatory lesions and establish fibrinogen as a key component of the coagulation cascade with pleiotropic functions in CNS innate and adaptive immunity.

In EAE, T cells enter the CNS after local activation by perivascular macrophages at the leptomeninges and their initial local CNS activation determines the clinical outcome of the autoimmune response ${ }^{18}$. Fibrin is localized in the leptomeninges at EAE pre-onset and induces early perivascular clustering of microglia and meningeal macrophages ${ }^{5}$. Moreover, in marmoset EAE early BBB leakage is associated with perivascular inflammatory cuffing and parenchymal microglial activation, but precedes demyelination ${ }^{6}$. Therefore, it is possible that within the CNS fibrin functions as an instructive signal enabling antigenpresenting properties in resident perivascular macrophages and thus facilitating T-cell entry, proliferation and activation. $\mathrm{MOG}_{35-}$ 55 tetramer binding in the cervical lymph nodes (Fig. 4b) and $\mathrm{MOG}_{35-55}$-induced BrdU incorporation (Fig. 4c) demonstrate the presence of functional autoreactive myelin antigen-specific $\mathrm{CD} 4^{+}$ $\mathrm{T}$ cells in $\mathrm{C} 57 \mathrm{BL} / 6$ mice injected with fibrinogen in the corpus callosum. Future studies will characterize the responses of $\mathrm{T}$ cells to other myelin antigens of not only C57BL/6 mice, but also in the 
a
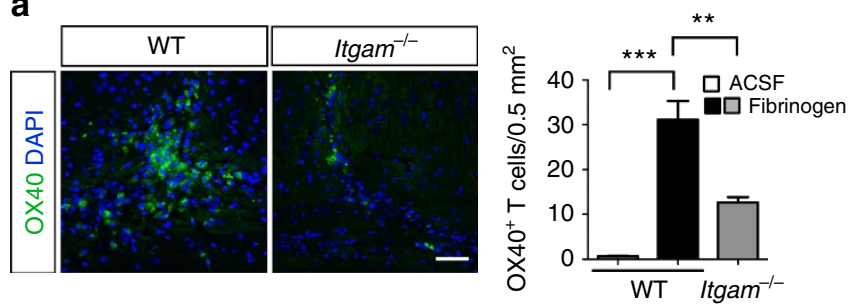

b

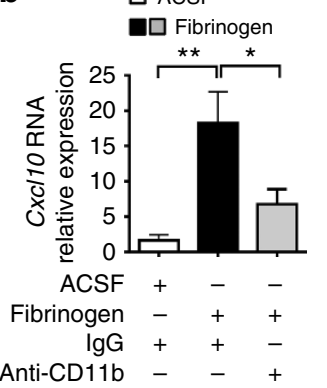

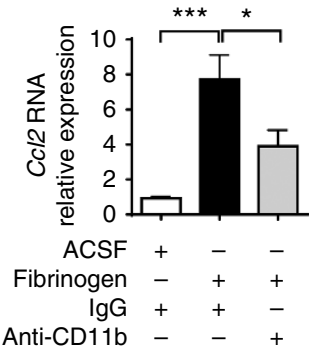

C

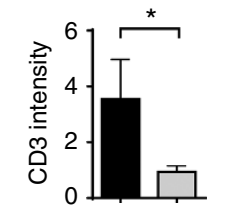

Fibrinogen ++

$\lg G+-$

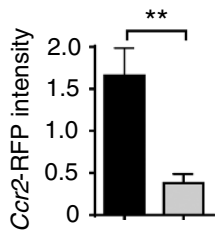

Fibrinogen + +

$\lg G+-$

d

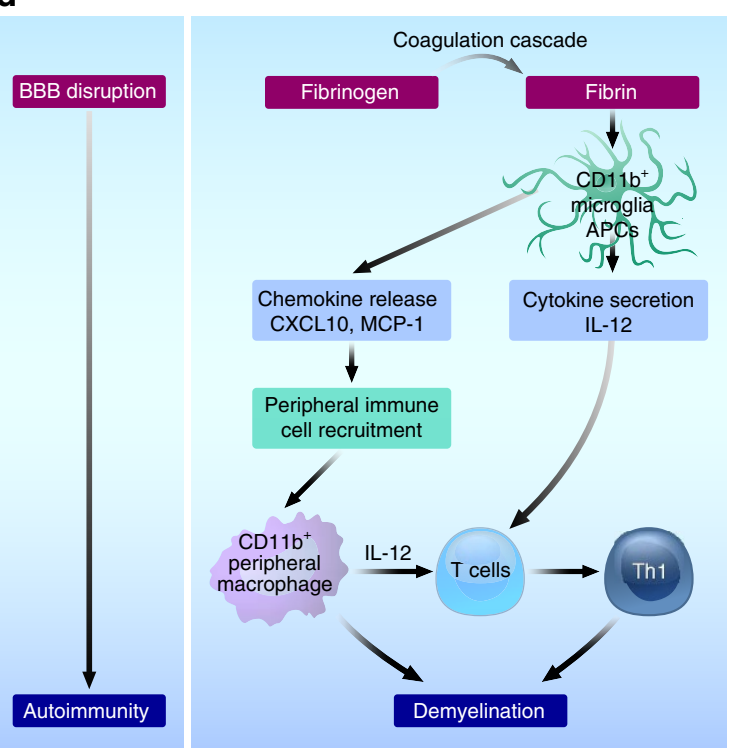

Figure 8 | Inhibition of CD11b blocks fibrinogen-induced local T-cell activation, chemokine gene expression and peripheral inflammatory cell recruitment. (a) Fibrinogen-induced local T-cell activation (OX-40) in the corpus callosum of WT mice is significantly reduced in Itgam ${ }^{-/}-$mice $(n=4)$. Representative images are shown. Data are presented as mean \pm s.e.m. ${ }^{\star \star} P<0.01$, ${ }^{\star \star \star} P<0.001$ (one-way ANOVA and Bonferroni's multiple comparisons test). Scale bar, $100 \mu \mathrm{m}$. (b) In vivo pharmacologic blockade of CD11b by intracerebroventricular delivery of anti-CD11b antibody reduces fibrinogen-induced $\mathrm{Cxc} / 10$ and $\mathrm{C} / 2$ gene expression, compared with isotype lgG control antibody. Data are presented as mean \pm s.e.m. ( $n=5$ per group). ${ }^{\star} P<0.05$, ${ }^{\star \star} P<0.01$, ${ }^{\star \star \star} P<0.001$ (one-way ANOVA and Bonferroni's multiple comparisons test). (c) Quantification of infiltrated CD3 ${ }^{+} \mathrm{T}_{\text {cells }}$ and RFP ${ }^{+}$macrophages in the corpus callosum 7 days after injection of fibrinogen in WT mice treated with anti-CD11b or lgG isotype control antibody. Data are presented as mean \pm s.e.m. (CD3, $n=6$-7 mice per group; RFP, $n=7$ mice per group). ${ }^{\star} P<0.05,{ }^{\star \star} P<0.01$ (non-parametric Mann-Whitney U-test). (d) Proposed model for the role of fibrin, the final product of the coagulation cascade, in the development of CNS autoimmunity. On BBB disruption, fibrinogen extravagates into the CNS and is converted to fibrin upon activation of coagulation. Fibrin, the high-affinity plasma-derived ligand for CD11b/CD18, activates CNS resident innate immune cells (microglia and perivascular macrophages) to stimulate chemokine release leading to recruitment of peripheral inflammatory macrophages/monocytes and T cells. Fibrin also induces antigen-presenting properties and provides instructive signals (such as IL-12) for inducing Th1-cell differentiation. Fibrin-induced microglial activation, recruitment of peripheral macrophages and T-cell activation lead to inflammatory demyelination. ANOVA, analysis of variance.

CNS and draining lymph nodes of other mouse strains. Since interactions of T cells with APCs also continue during the peak of $\mathrm{EAE}^{18}$, fibrin-induced activation of autoimmune responses might play a role not only at the onset but also for the amplification and perpetuation of the autoimmune response.

Strikingly, our study shows that extravascular fibrinogen induces a transcriptional program of immune effector-cell activation and recruitment that links innate with adaptive immunity. Upregulation of CXCL10 and IL-12p40, two immune modulators involved in T-cell recruitment and Th1-cell differentiation, occurs before the infiltration of peripheral leukocytes, suggesting that fibrinogen-induced activation of CNS innate immunity appears to be a primary pathogenic event that precedes T-cell entry into the CNS. Since CCL2-dependent recruitment of 
peripheral monocytes is required for antigen-specific Th1 immune responses ${ }^{26}$, fibrin-induced recruitment of peripheral monocytes might contribute to Th1-cell differentiation. Indeed, the fibrin-induced $I L-20 p 40$ expression in both microglia and BMDMs observed here suggests that both resident and peripheral $\mathrm{CD}_{11 \mathrm{~b}}{ }^{+}$innate immune cells can be activated by fibrin to enable autoimmune responses. Therefore, an attractive scenario based on the present findings is that weakening of the BBB either by peripheral brain autoimmune response or by exposure to highrisk environmental factor(s) that weaken the BBB, such as systemic inflammation and infection, extravascular fibrin deposition and activation of coagulation in the CNS might be key upstream signals for the activation of innate and adaptive immune responses.

The time-course study in $C \mathrm{cr} 2^{R F P /}+C x 3 c r 1^{G F P /+}$ mice showed that the primary effect of fibrinogen is on the resident $\mathrm{GFP}^{+}$ microglia and secondarily on the peripheral $\mathrm{RFP}^{+}$macrophages (Fig. 6). Indeed, morphologic changes in GFP-expressing microglia occur as early as 1 day after fibrinogen injection, while RFP-expressing macrophages are not detected in the CNS until 3 days after fibrinogen injection (Fig. 6a). Accordingly, increased chemokine gene expression in the corpus callosum is detected as early as $12 \mathrm{~h}$ after fibrinogen injection (Fig. 2a), before the infiltration of peripheral macrophages (Fig. 6a) and $\mathrm{T}$ cells (Fig. 1a). Notably, pharmacologic inhibition of CD11b in the CNS by intracerebroventricular delivery of M1/70 reduced chemokine expression and decreased peripheral macrophage infiltration (Fig. 8b,c), further suggesting that microglia are the primary cell target of fibrinogen in vivo. CD11b/CD18 is expressed in microglia and macrophages and regulates myelin phagocytosis ${ }^{11}$. It is possible that CD11b/CD18 engagement of extravascular fibrinogen induces activation of APC properties in innate immune cells in a hierarchical manner, first by activating microglia and then peripheral macrophages after they enter the CNS. Since peripheral macrophages enter into the CNS in neurodegenerative diseases associated with $\mathrm{BBB}$ and fibrin deposition, such as stroke and Alzheimer's disease ${ }^{47}$, fibrinogen might stimulate the recruitment of peripheral macrophages into the CNS in a wide spectrum of neurological diseases.

We established FIE as a novel experimental setting for exploring the cascade of pathogenic events that directly follow from the leakage of plasma proteins in the white matter in the absence of pre-existing peripheral immune activation or myelin pathology. We selected stereotactic delivery of fibrinogen as it is a common experimental method in viral- and toxin-induced demyelination $^{48}$, as well as in established neurodegeneration models, such as kainic acid injection in the hippocampus. Moreover, stereotactic delivery evades any complexities associated with the imposed genetic expression, assembly and processing of all three chains of fibrinogen. FIE could be used to dissect the contribution of $\mathrm{BBB}$ disruption and the coagulation cascade in the CNS without the confounding factors of preexisting viral, cytokine, toxin or autoimmune events. Given its rapid 7-day disease course, FIE could also be used as a pharmacodynamic model to rapidly test the efficacy of novel treatments for inhibiting CNS-targeted innate and adaptive immune responses. Using albumin, kininogen and plasma derived from $\mathrm{Fib}^{-1-}$ and Fib ${ }^{\gamma 77-395}$ mice, we show that fibrinogen is a major protein in the blood that drives sustained neuroinflammatory responses in the CNS. It is possible that in addition to fibrinogen, other plasma proteins might play a role in brain pathology. In particular, other components of the coagulation cascade involved in fibrin formation and clot stabilization, such as thrombin, factors X, XII and XIII could be involved in inflammatory responses ${ }^{49}$. Future studies will elucidate the relative contribution of blood proteins to brain inflammation and neurodegeneration. Our study demonstrates that fibrinogen induces demyelination using myelin-specific antibodies and histological stains that clearly show myelin loss. Demyelination can be associated with axonal damage in MS and Alzheimer's disease $\mathrm{s}^{50-52}$. Future studies will show whether fibrinogen-induced demyelination is primary associated with preservation of axons, or whether it is accompanied by axonal damage.

Our results may have broad implications for the potential development of new therapeutic strategies for neuroinflammatory diseases. Activation of $\mathrm{CD} 1 \mathrm{~b}^{+}$resident CNS cells appear to be one of the earliest events leading to local CNS antigen presentation, amplification of myelin-reactive $\mathrm{T}$-cell responses, infiltration of peripheral macrophages and axonal damage $5^{5,17,53,54}$. Since CD11b/CD18 is a pleiotropic receptor ${ }^{55}$, specific inhibition of its pathogenic ligand fibrinogen would be a preferred upstream therapeutic strategy for suppressing the pathogenic cascade in neuroinflammation over any global inhibition of CD11b/CD18. Selective disruption of CD11b/ CD18-fibrinogen interface would also be expected to protect the brain from axonal damage and neurodegeneration ${ }^{5}$. Importantly, targeting the interaction of fibrinogen with CD11b would not affect the beneficial functions of fibrinogen in haemostasis $^{1,11}$. Since activation of innate immunity is a hallmark of neuroimmune and neurodegenerative diseases, inhibiting the interaction of fibrinogen with CD11b/CD18 could be beneficial not only for suppressing autoimmunity, but also halting neurodegeneration. Identification of extravascular fibrinogen as a key regulator of CNS innate and adaptive immunity might allow us to develop novel therapies targeting early and late events in neuroinflammatory diseases and potentially provide new treatment options.

\section{Methods}

Mice. C57BL/6 MHC II ${ }^{-1-}$ (ref. 28), Cxcl10-I- (ref. 29), Itgam $^{-1-}$ (ref. 45), $C \times 3 c r 1^{G F P /+}$ (ref. 56), MOG-specific TCR transgenic mice (2D2) ${ }^{31}$ and SJL/J were purchased from the Jackson Laboratory. C57BL/6 Fib ${ }^{-1-}$ (ref. 19), Fib ${ }^{2390-396 A}$ mice $^{22}$, OVA-specific TCR-transgenic mice (OT-II) ${ }^{32}, R_{A} 1^{-1}$ - (ref. 57), $R A G 2^{-1-} \gamma c^{-1-}$ (ref. 30) and Ccr $2^{R F P / R F P}$ mice ${ }^{42}$ were also used. C57BL/6 $C c r 2^{R F P / R F P}$ mice were crossed with $C x 3 c r 1^{G F P / G F P}$ mice to generate $C \times 3 c r 1^{G F P /}$ ${ }^{+} \mathrm{Ccr} 2^{R F P /}+$ mice. All animal experiments were performed on adult male mice at 10-15 weeks of age. Mice were housed in the groups of five per cage under standard vivarium conditions and a 12-h light/dark cycle. All animal protocols were approved by the Committee of Animal Research at the University of California, San Francisco, and in accord with the National Institutes of Health guidelines.

Stereotactic injections in the corpus callosum. Mice were anaesthetized with avertin and placed in a stereotactic apparatus. Plasma plasminogen-free fibrinogen (Calbiochem) was dissolved in endotoxin-free distilled water (HyClone), diluted to $5 \mathrm{mg} \mathrm{ml}^{-1}$ with ACSF. Fibrinogen $\left(1 \mu \mathrm{l}\right.$ of $\left.5 \mathrm{mg} \mathrm{ml}^{-1}\right)$, ACSF, albumin $(1 \mu \mathrm{lof}$ $\left.5 \mathrm{mg} \mathrm{ml}^{-1}\right)$ or kininogen $\left(1 \mu \mathrm{lof} 0.1 \mathrm{mg} \mathrm{ml}^{-1}\right)$ were slowly injected $\left(0.3 \mu \mathrm{lmin}^{-1}\right)$ with a $10-\mu$ l Hamilton syringe attached to a $33-\mathrm{G}$ needle into the brain at coordinates (anteroposterior, $-1.0 \mathrm{~mm}$; mediolateral, $-1.0 \mathrm{~mm}$; dorsoventral, $-1.75 \mathrm{~mm}$ from the bregma, according to Paxinos and Watson) as described ${ }^{5}$ Plasma was isolated and injected as described ${ }^{5}$.

Intracerebroventricular delivery of antibody. Functional-grade purified antiCD11b (M1/70; eBioscience), or isotype control IgG (eBioscience), was injected

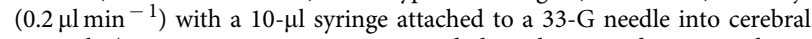
ventricle (anteroposterior, $-2.0 \mathrm{~mm}$; mediolateral, $0 \mathrm{~mm}$, dorsoventral, $-2.0 \mathrm{~mm}$ ) $30 \mathrm{~min}$ before fibrinogen injection.

Stereotactic injections in the spinal cord. Mice were anaesthetized by intraperitoneal injection of ketamine $\left(100 \mathrm{mg} \mathrm{kg}^{-1}\right)$ and xylazine $\left(15 \mathrm{mg} \mathrm{kg}^{-1}\right)$. A midline skin incision was made over the upper lumbar regions of spinal cord. The spinal column was secured via the mouse vertebral clamps fixed in a stereotaxic frame. The epidural space was exposed by disruption of the L1-L2 interspinous ligament without laminectomy as described ${ }^{58}$. A pulled glass micropipette prefilled with fibrinogen was inserted into the spinal cord at coordinates $(0.3-\mathrm{mm}$ lateral to the spinal midline, a depth of $0.9 \mathrm{~mm}$ from the 
spinal cord surface). Fibrinogen $\left(1 \mu \mathrm{l} \mathrm{of} 5 \mathrm{mg} \mathrm{ml}^{-1}\right)$ was injected $\left(0.2 \mu \mathrm{l} \mathrm{min}{ }^{-1}\right)$ and the glass micropipette remained in place for $5 \mathrm{~min}$ before slowly withdrawn. After surgery, the muscles and skin were sutured, and mice were allowed to recover.

Expression of recombinant fibrinogen. For the production of recombinant fibrinogen, freestyle HEK293T cells were transiently co-transfected with three eukaryotic expression vectors containing full-length complementary DNA (cDNA) for the three chains of fibrinogen, alpha $(1.9 \mathrm{~kb})$, beta $(1.3 \mathrm{~kb})$ and gamma $(1.3 \mathrm{~kb})$, according to the standard procedures. At day 4 post transfection, medium was collected and the supernatant was passed through a Vivaspin-20 concentrator with cutoff 100,000 molecular weight cutoff and was added to a Slide-A-Lyzer Dialysis cassette with cutoff 10,000 molecular weight cutoff for overnight dialysis in PBS buffer at $40{ }^{\circ} \mathrm{C}$ with stirring. Expression of the recombinant fibrinogen protein was evaluated by SDS-polyacrylamide gel electrophoresis gel electrophoresis and Coomassie staining.

Histology and immunohistochemistry. Mice were transcardially perfused with $4 \%$ paraformaldehyde under avertin anaesthesia. Brains and spinal cord were removed, postfixed, processes for paraffin embedding. Luxol fast blue staining and immunohistochemistry were performed as described ${ }^{11,59,60}$. For toluidine blue staining, animals were intracardially perfused under deep ether anaesthesia with ice-cold $2 \%$ paraformaldehyde, $0.5 \%$ glutaraldehyde in $0.1 \mathrm{moll}^{-1}$ phosphate buffer, $\mathrm{pH} 7.2$, for $1 \mathrm{~min}$, followed by ice-cold $3 \%$ glutaraldehyde in $0.1 \mathrm{moll}^{-1}$ phosphate buffer for $5 \mathrm{~min}$. Brains were removed, immersion-fixed for $24 \mathrm{~h}$ in phosphate-buffered 3\% glutaraldehyde, postfixed in $2 \%$ osmium tetroxide solution and subsequently embedded in epoxy resin. Semi-thin sections were cut and stained with toluidine blue. For immunohistochemistry, sections were permeabilized in $0.1 \%$ Triton X-100, blocked with $5 \%$ bovine serum albumin and $5 \%$ normal donkey serum, and incubated for $24 \mathrm{~h}$ at $4{ }^{\circ} \mathrm{C}$ with primary antibodies. Primary antibodies were rabbit anti-Iba-1 (1:1,000, Wako), rabbit anti-CD3 (1:1,000, Dako), rabbit anti-GFAP (1:500, Sigma), mouse anti-MBP (1:100, Covance), rat anti-mouse MHC class II (1:200, BMA Biomedicals) or goat antimouse CXCL10 (1:200, R\&D system). Sections were rinsed in PBS with $0.1 \%$ Triton X-100 and incubated with secondary antibodies conjugated with Alexa Fluor 488 or 594 (1:200, Jackson Immunochemicals) for $1 \mathrm{~h}$ in the dark. Immunohistochemistry using the primary anti-MBP monoclonal antibody was performed with the MOM kit (Vector) according to the manufacturer's instruction. After washing in PBS, sections were mounted on glass slides and coverslipped with Prolong Gold antifading agent (Invitrogen). Images were acquired using an Axioplan II epifluorescence microscope (Zeiss) equipped with dry Plan-Neofluar objectives $(10 \times 0.3$ numerical aperture $(\mathrm{NA}), 20 \times 0.5 \mathrm{NA}$ or $40 \times 0.75 \mathrm{NA})$. Quantification was performed on thresholded images using ImageJ by blinded observers.

Flow cytometry. Mice were perfused with saline and brain slices were prepared using the adult mouse brain slicer matrix (Zivic Instruments). Corpus callosal area was dissected from the slices and minced tissue was digested using collagenase IV (Roche) at $37^{\circ} \mathrm{C}$ for $30 \mathrm{~min}$. Cell suspensions were filtered through a $70-\mu \mathrm{m}$-cell strainer (BD Falcon). Cell suspensions were prepared in RPMI-1640 (Invitrogen), supplemented with $5 \%$ (vol/vol) heat-inactivated fetal bovine serum (FBS, Invitrogen), $50 \mathrm{U}$ penicillin-streptomycin (Invitrogen) and $50 \mu \mathrm{M} \beta$-mercaptoethanol (Invitrogen). Single-cell suspensions were incubated with Myelin Removal Beads (Miltenyi Biotec), and cells were collected by autoMACs Pro Separator (Miltenyi Biotec). Intracellular staining of splenocytes derived from mice undergoing $\mathrm{MOG}_{35-55} \mathrm{EAE}^{5,11}$ was used as positive control for fluorescence-activated cell sorting antibody staining. For cytokine analysis, cells were incubated for $4 \mathrm{~h}$ with phorbol 12 -myristate 13 -acetate $\left(50 \mathrm{ng} \mathrm{ml}^{-1}\right.$, Sigma), ionomycin $\left(500 \mathrm{ng} \mathrm{ml}^{-1}\right.$, Sigma) and Golgi-Plug (BD Biosciences) and surface stained with anti-CD3-PE (eBioscience), anti-CD4-APC-Cy7 (eBioscience) and anti-CD8-PacBlue (eBioscience). Cells were then fixed with Cytofix/Cytoperm solution (BD Biosciences), and intracellular cytokine staining was performed with anti-IFN- $\gamma$ PE-Cy7 (eBioscience), anti-IL-4-Alexa 647 (eBioscience) and anti-IL-17a-FITC (eBioscience). All labelled antibodies were used at 1:300 dilutions. Flow cytometric analysis was performed on an LSR II (BD Biosciences). Data were analysed using the FlowJo software (Tree Star).

Detection of endogenous MOG antigen-specific T cells. Fibrinogen-injected brains and its draining lymph nodes were removed at 7 days post injection, and single-cell suspensions were prepared as described above. Prepared lymphocytes were stimulated with $20 \mu \mathrm{g} \mathrm{ml}^{-1} \mathrm{MOG}_{35-55}$ for 7 days. Endogeneous MOG antigen-specific $\mathrm{T}$ cells were identified with $\mathrm{MOG}_{35-55}$-specific T-select I-A $\mathrm{A}^{\mathrm{b}} \mathrm{MOG}_{35-55}$ tetramer (MBL). I-A ${ }^{\mathrm{b}} \mathrm{OVA}_{323-339}$ Tetramer (MBL) was used as a negative control. Cultured cells were resuspended in FCM buffer ( $\left.2 \% \mathrm{FCS} / 0.05 \% \mathrm{NaN}_{3} / \mathrm{PBS}\right)$ and incubated with FcR-blocking antibody for $5 \mathrm{~min}$ at room temperature. Cells were incubated with I- $\mathrm{A}^{\mathrm{b}} \mathrm{MOG}_{35-55}$ tetramer for $60 \mathrm{~min}$ at $4{ }^{\circ} \mathrm{C}$ followed by anti-CD4FITC incubation for $30 \mathrm{~min}$ at $4{ }^{\circ} \mathrm{C}$. After two washes with FCM buffer, cells were analysed with an LSR II.
T-cell CFSE staining and adoptive transfer. Naive $2 \mathrm{D} 2 \mathrm{CD} 4^{+} \mathrm{T}$ cells were isolated from spleens and lymph nodes of $2 \mathrm{D} 2$ mice using $\mathrm{CD} 4{ }^{+}{ }^{\mathrm{CD}} 62 \mathrm{~L}^{+} \mathrm{T}$-cell isolation kits (Miltenyi Biotec). Isolated T cells were labelled with CFSE $^{35}$ (Invitrogen) at room temperature. A total of $1 \times 10^{7}$ cells were transferred intraperitoneally into recipient $24 \mathrm{~h}$ before ACSF and fibrinogen injection into the corpus callosum. On day 6 , labelled $\mathrm{T}$ cells were isolated from the brains, and the frequency of $\mathrm{CFSE}^{+}\left(\mathrm{CFSE}_{\text {low }}\right) \mathrm{TCR}-\mathrm{V} \beta 11^{+} \mathrm{CD}^{+} \mathrm{T}$ cells was analysed by flow cytometry. For analysis of CNS migratory activity of $2 \mathrm{D} 2$ or OT-II CD4 ${ }^{+} \mathrm{T}$ cells, isolated naive $2 \mathrm{D} 2$ or OT-II CD4 ${ }^{+}$T cells were co-cultured 3 days with BMDMs incubated with either $20 \mu \mathrm{g} \mathrm{ml}^{-1} \mathrm{MOG}_{35-55}$ or $\mathrm{OVA}_{323-339}$ peptide together with or without fibrin. Cells were then labelled with CFDA-SE according to the manufacturer's instructions (Invitrogen) and injected $\left(1 \times 10^{7}\right.$ cells per mouse) into the $R a g 1^{-1-}$ recipient mice that had been injected with fibrinogen 2 days before. Three days after post-T-cell injection, mice were killed, and their brains were subjected to histological analysis.

Isolation of primary microglia. Microglia were prepared from neonatal rat or mouse pups at postnatal day $(\mathrm{P}) 2-3$. The cortices were separated from meninges and minced with a sterile razor blade. Tissue pieces were transferred into $2.5 \%$ Trypsin solution (Life Technologies/Gibco) containing DNAse (SIGMA). After incubation at $37^{\circ} \mathrm{C}$ for $25 \mathrm{~min}$ the trypsin solution was removed, cortices were washed with 30\% FBS in DPBS and serially triturated with 30\% FBS in Dulbecco's phosphate-buffered saline (DPBS) (Life Technologies/Gibco) containing DNAse. The cell suspension was gently spun at $200 \mathrm{~g}$ for $15 \mathrm{~min}$ and the pellet resuspended in DMEM (Life Technologies/Gibco), containing 10\% FBS (Life Technologies/ Gibco), 100 units per millilitre penicillin and $100 \mathrm{mg} \mathrm{ml}^{-1}$ streptomycin (Life Technologies/Gibco). Cells were plated into poly-D-lysine pre-coated T-75 flasks at a density of 2-3 cortices per flask. On day 3 in vitro, fresh medium was added and cells were grown for 1 more day. On day 4 in vitro, flasks were placed onto a shaker platform, preheated to $37^{\circ} \mathrm{C}$ and microglia cells were shaken off the cortical cell layer at 200 r.p.m. for $2 \mathrm{~h}$. The medium containing mostly microglia cells was removed from the flasks and cells were spun at $200 \mathrm{~g}$ for $15 \mathrm{~min}$. The cell pellets were gently resuspended in culture medium and the microglia density was adjusted to 5000 cells per microlitre.

Isolation of BMDMs. BMDMs were prepared as described ${ }^{61}$. In brief, bone marrow cells were isolated from tibia and femur of 10 -week-old mice and cultured in RPMI-1640 (Invitrogen) supplemented with $10 \%$ (vol/vol) heat-inactivated FBS (Invitrogen), $50 \mathrm{U}$ penicillin-streptomycin (Invitrogen), $50 \mu \mathrm{M} \beta$-mercaptoethanol and murine M-CSF $\left(10 \mathrm{ng} \mathrm{ml}^{-1}\right)$. On day 6, adherent BMDMs were harvested from plates by the addition of PBS containing $5 \mathrm{mM}$ EDTA for experiments.

Fibrin stimulation of microglia or BMDMs. To prepare soluble fibrin ${ }^{62}$, human plasma fibrinogen (Calbiochem) was converted to fibrin by mixing with thrombin. Fibrin clots were cut into small pieces and fragmented by sonication. Clot fragments are filtered through sieves, their concentration was determined, and they were stored at $-80^{\circ} \mathrm{C}$. Soluble fibrin preparations were tested for LPS and thrombin activity and were shown to have undetectable amounts of contaminants. Cultures were treated with soluble fibrin by adding soluble fibrin to the supernatant. To prepare fibrin-coated plates, a mixture of thrombin $\left(1 \mathrm{U} \mathrm{ml}^{-1}\right.$ Sigma) and $\mathrm{CaCl}_{2}(7 \mathrm{mM}$, Sigma) in HEPES buffer was added into each well of tissue culture plates (TPP Techno Plastic Products AG, Switzerland) and subsequently $50 \mathrm{\mu g} \mathrm{ml}^{-1}$ of human plasma fibrinogen (Calbiochem) was added. The plates were incubated for $1 \mathrm{~h}$ at $37^{\circ} \mathrm{C}$. After incubation, solution was evaporated, and moisture retention was minimized by air flow through the dryer system. After washing the plates with PBS, microglia or BMDMs were seeded on fibrin-coated plates. All reagents were made in endotoxin-free water.

T-cell proliferation assay. $\mathrm{CD} 4^{+} \mathrm{T}$ cells were purified from the spleen with $\mathrm{CD} 4{ }^{+} \mathrm{CD} 62 \mathrm{~L}^{+} \mathrm{T}$-cell isolation kits (Miltenyi Biotec). $\mathrm{CD} 4{ }^{+} \mathrm{T}$ cells were mixed with BMDM at the ratio (1:5). T-cell proliferation was assessed by BrdU incorporation kit (BD Bioscience) during last $24 \mathrm{~h}$ of culture. For antigen-specific T-cell proliferation, $\mathrm{CD} 4{ }^{+} \mathrm{T}$ cells isolated from $2 \mathrm{D} 2$ mice were cultured with $\mathrm{MOG}_{35-55}$ peptide $\left(20 \mu \mathrm{g} \mathrm{ml}^{-1}\right)$ for 4 days in the presence of BMDM treated with fibrin or primary mouse microglia plated on fibrin-coated plates or stimulated with LPS $\left(200 \mathrm{ng} \mathrm{ml}^{-1}\right)$ for $24 \mathrm{~h}$. Cells were then fixed, permeabilized and stained with FITC-conjugated anti-BrdU (BrdU Flow Kits). For measurement of PLP antigenspecific $\mathrm{CD} 4{ }^{+} \mathrm{T}$-cell proliferation, lymphocytes were isolated from the draining lymph nodes of SJL/J mice at 7 days after fibrinogen and ACSF injection into the corpus callosum. Lymphocytes were stimulated with PLP $_{139-151}$ peptide $\left(20 \mu \mathrm{g} \mathrm{ml}^{-1}\right)$ and PLP $178-191$ peptide $\left(20 \mu \mathrm{g} \mathrm{ml}^{-1}\right)$, and IL-2 $\left(10 \mathrm{ng} \mathrm{ml}^{-1}\right)$ was added every 2 days. BrdU incorporation was assessed as described above. For intracellular cytokine staining, $\mathrm{CD} 4^{+} \mathrm{T}$ cells were stimulated with $20 \mu \mathrm{g} \mathrm{ml}^{-1}$ $\mathrm{MOG}_{35-55}$ peptide for $72 \mathrm{~h}$ and restimulated with PMA and ionomycin for $4 \mathrm{~h}$ in the presence of Golgi-Plug (BD Bioscience), after which IFN- $\gamma$-, IL-4- and IL-17producing cells were analysed by intracellular staining. 
RNA isolation and quantitative PCR. RNA was isolated from brain samples with the RNAeasy kit (Qiagen), according to the manufacturer's instructions. RNA was reverse-transcribed to cDNA using the GeneAmp RNA PCR Core kit (Applied Biosystems) and random hexamer primers. Real-time PCR analysis was performed using the Step One Plus (Applied Biosystems) and the Quantitect SYBR Green PCR kit (Qiagen) with $2 \mu \mathrm{l}$ of cDNA template in a $25-\mu \mathrm{l}$ reaction. Results were analysed using the Opticon 2 Software and the comparative CT method. Data are expressed as $2^{\mathrm{A} A C T}$ for the experimental gene of interest normalized to the housekeeping gene and presented as fold change relative to control. The gene-specific primers are listed in Supplementary Table 3.

\section{Gene expression profiling by microarray analysis. Microarray analysis was} performed on cultured rat microglia treated with fibrin or BMDMs plated on fibrin-coated plates and brain tissues from ACSF- and fibrinogen-injected mice. Rat pups were used to isolate highly pure microglial cultures in sufficient numbers for microarray analysis. For brain tissue microarray analysis, corpus callosal area was dissected from brain slices prepared with brain slicer matrix (Zivic instruments). Total RNA was isolated using RNeasy Mini kit/RNeasy Lipid tissue mini kit (QIAGEN) according to the manufacturer's instruction. Probes were prepared using NuGEN Ovation Pico WTA V2 kit and NuGEN Encore Biotin Module, and hybridized to Rat and Mouse Gene 1.0 ST GeneChip arrays (Affymetrix). Arrays were scanned using an Affymetrix GCS3000 scanner and Affymetrix Command Console software, and data were normalized using the RMA algorithm in Affymetrix Expression Console. Microarrays were normalized for array-specific effects using Affymetrix's 'Robust Multi-Array' normalization. Normalized array values were reported on a $\log 2$ scale. For statistical analyses, we removed all array probe sets where no experimental groups had an average $\log 2$ intensity $>3.0$. This is a standard cutoff, below which expression is indistinguishable from background noise. Linear models were fitted for each gene using the Bioconductor 'limma' package in $\mathrm{R}^{63}$. Moderated $t$-statistics, fold change and the associated $P$ values were calculated for each gene. To account for the fact that thousands of genes were tested, we reported false discovery rate (FDR)-adjusted values, calculated using the Benjamini-Hochberg method ${ }^{64}$. FDR values indicate the expected fraction of falsely declared, differentially expressed (DE) genes among the total set of declared $\mathrm{DE}$ genes (that is, $\mathrm{FDR}=0.15$ would indicate that $\sim 15 \%$ of the declared $\mathrm{DE}$ genes were expected to be due to experimental noise instead of actual differential expression). The microarray data have been deposited in the Gene Expression Omnibus (GEO) database accession number GSE71084.

Induction of EAE and systemic fibrinogen depletion. EAE was induced in 8-week-old female SJL/J by subcutaneous immunization with $100 \mu \mathrm{gLP}_{139-151}$ (HSLGKWLGHPDKF; Auspep Pty Ltd) as described ${ }^{11}$. Mice were depleted of fibrinogen with ancrod as described ${ }^{11}$. The mice received $2.4 \mathrm{U}$ ancrod per day by mini-osmotic pump. In control animals, buffer-filled minipumps were implanted. On day 9 of immunization, draining lymph node T cells were obtained from EAE mice and cultured with PLP $_{139-151}$ peptide for the detection of intracellular IFN- $\gamma$ and IL- 4 in $\mathrm{CD} 4^{+} \mathrm{T}$ cells and BrdU proliferation assay as described above.

Statistical analyses. The data are presented as mean \pm s.e.m. Statistical calculations were performed using the GraphsPad Prism. Data distribution was assumed to be normal, but this was not formally tested. No statistical methods were used to predetermine sample size, but our sample sizes are similar to those reported previously $y^{5,11,59}$. Statistical significance was determined with non-parametric twosided Mann-Whitney $U$-test, one-way, or two-way, analysis of variance followed by Bonferroni post test (multiple comparisons). Mice and cells were divided into experimental groups in an unbiased manner. No randomization was used to assign groups or collect data. All animals survived until the end of the study and all data points were included in analysis. All histopathological analysis was performed by a blinded observer.

\section{References}

1. Davalos, D. \& Akassoglou, K. Fibrinogen as a key regulator of inflammation in disease. Semin. Immunopathol. 34, 43-62 (2012).

2. Marik, C., Felts, P. A., Bauer, J., Lassmann, H. \& Smith, K. J. Lesion genesis in a subset of patients with multiple sclerosis: a role for innate immunity? Brain 130, 2800-2815 (2007).

3. Vos, C. M. et al. Blood-brain barrier alterations in both focal and diffuse abnormalities on postmortem MRI in multiple sclerosis. Neurobiol. Dis. 20, 953-960 (2005).

4. Davalos, D. et al. Early detection of thrombin activity in neuroinflammatory disease. Ann. Neurol. 75, 303-308 (2014).

5. Davalos, D. et al. Fibrinogen-induced perivascular microglial clustering is required for the development of axonal damage in neuroinflammation. Nat. Commun. 3, 1227 (2012).

6. Maggi, P. et al. The formation of inflammatory demyelinated lesions in cerebral white matter. Ann. Neurol. 76, 594-608 (2014).

7. Han, M. H. et al. Proteomic analysis of active multiple sclerosis lesions reveals therapeutic targets. Nature 451, 1076-1081 (2008)

8. Gay, D. \& Esiri, M. Blood-brain barrier damage in acute multiple sclerosis plaques. An immunocytological study. Brain 114, 557-572 (1991).
9. Claudio, L., Raine, C. S. \& Brosnan, C. F. Evidence of persistent blood-brain barrier abnormalities in chronic- progressive multiple sclerosis. Acta. Neuropathol. 90, 228-238 (1995).

10. Kirk, J., Plumb, J., Mirakhur, M. \& McQuaid, S. Tight junctional abnormality in multiple sclerosis white matter affects all calibres of vessel and is associated with blood-brain barrier leakage and active demyelination. J. Pathol. 201, 319-327 (2003).

11. Adams, R. A. et al. The fibrin-derived gamma377-395 peptide inhibits microglia activation and suppresses relapsing paralysis in central nervous system autoimmune disease. J. Exp. Med. 204, 571-582 (2007).

12. Paterson, P. Y., Koh, C. S. \& Kwaan, H. C. Role of the clotting system in the pathogenesis of neuroimmunologic disease. Fed. Proc. 46, 91-96 (1987).

13. Koh, C. S. \& Paterson, P. Y. Suppression of clinical signs of cell-transferred experimental allergic encephalomyelitis and altered cerebrovascular permeability in Lewis rats treated with a plasminogen activator inhibitor. Cell. Immunol. 107, 52-63 (1987).

14. Akassoglou, K. et al. Fibrin depletion decreases inflammation and delays the onset of demyelination in a tumor necrosis factor transgenic mouse model for multiple sclerosis. Proc. Natl Acad. Sci. USA 101, 6698-6703 (2004).

15. Inoue, A. et al. Fibrin deposition in the central nervous system correlates with the degree of Theiler's murine encephalomyelitis virus-induced demyelinating disease. J. Neuroimmunol. 77, 185-194 (1997).

16. Ozturk, A. et al. MRI of the corpus callosum in multiple sclerosis: association with disability. Mult. Scler. 16, 166-177 (2010).

17. Weber, M. S. et al. Type II monocytes modulate T cell-mediated central nervous system autoimmune disease. Nat. Med. 13, 935-943 (2007).

18. Lodygin, D. et al. A combination of fluorescent NFAT and H2B sensors uncovers dynamics of $\mathrm{T}$ cell activation in real time during CNS autoimmunity. Nat. Med. 19, 784-790 (2013).

19. Suh, T. T. et al. Resolution of spontaneous bleeding events but failure of pregnancy in fibrinogen-deficient mice. Genes Dev. 9, 2020-2033 (1995).

20. Lishko, V. K., Kudryk, B., Yakubenko, V. P., Yee, V. C. \& Ugarova, T. P. Regulated unmasking of the cryptic binding site for integrin alpha $\mathrm{M}$ beta 2 in the gamma C-domain of fibrinogen. Biochemistry 41, 12942-12951 (2002).

21. Ugarova, T. P. et al. Sequence gamma 377-395(P2), but not gamma 190-202(P1), is the binding site for the alpha MI-domain of integrin alpha M beta 2 in the gamma C-domain of fibrinogen. Biochemistry 42, 9365-9373 (2003).

22. Flick, M. J. et al. Leukocyte engagement of fibrin(ogen) via the integrin receptor alphaMbeta2/Mac-1 is critical for host inflammatory response in vivo. J. Clin. Invest. 113, 1596-1606 (2004).

23. Ramaglia, V. et al. C3-dependent mechanism of microglial priming relevant to multiple sclerosis. Proc. Natl Acad. Sci. USA 109, 965-970 (2012).

24. Irvine, D. J., Purbhoo, M. A., Krogsgaard, M. \& Davis, M. M. Direct observation of ligand recognition by T cells. Nature 419, 845-849 (2002).

25. Fife, B. T. et al. CXCL10 (IFN-gamma-inducible protein-10) control of encephalitogenic CD4 + T cell accumulation in the central nervous system during experimental autoimmune encephalomyelitis. J. Immunol. 166, 7617-7624 (2001).

26. Huang, D. R., Wang, J., Kivisakk, P., Rollins, B. J. \& Ransohoff, R. M. Absence of monocyte chemoattractant protein 1 in mice leads to decreased local macrophage recruitment and antigen-specific $\mathrm{T}$ helper cell type 1 immune response in experimental autoimmune encephalomyelitis. J. Exp. Med. 193, 713-726 (2001).

27. Ransohoff, R. M. \& Cardona, A. E. The myeloid cells of the central nervous system parenchyma. Nature 468, 253-262 (2010).

28. Madsen, L. et al. Mice lacking all conventional MHC class II genes. Proc. Natl Acad. Sci. USA 96, 10338-10343 (1999).

29. Dufour, J. H. et al. IFN-gamma-inducible protein 10 (IP-10; CXCL10)-deficient mice reveal a role for IP-10 in effector T cell generation and trafficking. J. Immunol. 168, 3195-3204 (2002).

30. Shinkai, Y. et al. RAG-2-deficient mice lack mature lymphocytes owing to inability to initiate V(D)J rearrangement. Cell 68, 855-867 (1992).

31. Bettelli, E. et al. Myelin oligodendrocyte glycoprotein-specific $\mathrm{T}$ cell receptor transgenic mice develop spontaneous autoimmune optic neuritis. J. Exp. Med. 197, 1073-1081 (2003).

32. Barnden, M. J., Allison, J., Heath, W. R. \& Carbone, F. R. Defective TCR expression in transgenic mice constructed using cDNA-based alpha- and betachain genes under the control of heterologous regulatory elements. Immunol. Cell Biol. 76, 34-40 (1998).

33. Mack, C. L., Vanderlugt-Castaneda, C. L., Neville, K. L. \& Miller, S. D. Microglia are activated to become competent antigen presenting and effector cells in the inflammatory environment of the Theiler's virus model of multiple sclerosis. J. Neuroimmunol. 144, 68-79 (2003).

34. Molnarfi, N. et al. MHC class II-dependent B cell APC function is required for induction of CNS autoimmunity independent of myelin-specific antibodies. J. Exp. Med. 210, 2921-2937 (2013). 
35. Quah, B. J., Warren, H. S. \& Parish, C. R. Monitoring lymphocyte proliferation in vitro and in vivo with the intracellular fluorescent dye carboxyfluorescein diacetate succinimidyl ester. Nat. Protoc. 2, 2049-2056 (2007).

36. Pesic, M. et al. 2-photon imaging of phagocyte-mediated $\mathrm{T}$ cell activation in the CNS. J. Clin. Invest. 123, 1192-1201 (2013).

37. Korn, T. et al. Myelin-specific regulatory T cells accumulate in the CNS but fail to control autoimmune inflammation. Nat. Med. 13, 423-431 (2007).

38. O'Connor, K. C. et al. Self-antigen tetramers discriminate between myelin autoantibodies to native or denatured protein. Nat. Med. 13, 211-217 (2007).

39. Stromnes, I. M., Cerretti, L. M., Liggitt, D., Harris, R. A. \& Goverman, J. M. Differential regulation of central nervous system autoimmunity by $\mathrm{T}(\mathrm{H}) 1$ and $\mathrm{T}(\mathrm{H}) 17$ cells. Nat. Med. 14, 337-342 (2008).

40. Bettelli, E. et al. Reciprocal developmental pathways for the generation of pathogenic effector TH17 and regulatory T cells. Nature 441, 235-238 (2006).

41. Hsieh, C. S. et al. Development of Th1 Cd4 + T-Cells through Il-12 Produced by Listeria-Induced Macrophages. Science 260, 547-549 (1993).

42. Saederup, N. et al. Selective chemokine receptor usage by central nervous system myeloid cells in CCR2-red fluorescent protein knock-in mice. PLoS One 5, e13693 (2010).

43. Ajami, B., Bennett, J. L., Krieger, C., McNagny, K. M. \& Rossi, F. M. Infiltrating monocytes trigger EAE progression, but do not contribute to the resident microglia pool. Nat. Neurosci. 14, 1142-1149 (2011).

44. Mildner, A. et al. CCR2 + Ly-6Chi monocytes are crucial for the effector phase of autoimmunity in the central nervous system. Brain 132, 2487-2500 (2009).

45. Coxon, A. et al. A novel role for the beta 2 integrin CD11b/CD18 in neutrophil apoptosis: a homeostatic mechanism in inflammation. Immunity 5, 653-666 (1996).

46. Weinberg, A. D. et al. Selective depletion of myelin-reactive T cells with the anti-OX-40 antibody ameliorates autoimmune encephalomyelitis. Nat. Med. 2, 183-189 (1996).

47. Merlini, M., Davalos, D. \& Akassoglou, K. In vivo imaging of the neurovascular unit in CNS disease. Intravital 1, 87-94 (2012).

48. Mix, E., Meyer-Rienecker, H., Hartung, H. P. \& Zettl, U. K. Animal models of multiple sclerosis-Potentials and limitations. Prog. Neurobiol. 92, 386-404 (2010).

49. Akassoglou, K. Coagulation takes center stage in inflammation. Blood $\mathbf{1 2 5}$, 419-420 (2015).

50. Trapp, B. D. et al. Axonal transection in the lesions of multiple sclerosis. N. Engl. J. Med. 338, 278-285 (1998).

51. Carmeli, C. et al. Demyelination in mild cognitive impairment suggests progression path to Alzheimer's disease. PLoS One 8, e72759 (2013).

52. Gouw, A. A. et al. Heterogeneity of white matter hyperintensities in Alzheimer's disease: post-mortem quantitative MRI and neuropathology. Brain 131, 3286-3298 (2008).

53. McMahon, E. J., Bailey, S. L., Castenada, C. V., Waldner, H. \& Miller, S. D. Epitope spreading initiates in the CNS in two mouse models of multiple sclerosis. Nat. Med. 11, 335-339 (2005).

54. Nikic, I. et al. A reversible form of axon damage in experimental autoimmune encephalomyelitis and multiple sclerosis. Nat. Med. 17, 495-499 (2011).

55. Schafer, D. P. et al. Microglia sculpt postnatal neural circuits in an activity and complement-dependent manner. Neuron 74, 691-705 (2012).

56. Jung, S. et al. Analysis of fractalkine receptor CX3CR1 function by targeted deletion and green fluorescent protein reporter gene insertion. Mol. Cell. Biol. 20, 4106-4114 (2000).

57. Mombaerts, P. et al. RAG-1-deficient mice have no mature B and T lymphocytes. Cell 68, 869-877 (1992).

58. Sheng, H. et al. A no-laminectomy spinal cord compression injury model in mice. J. Neurotrauma 21, 595-603 (2004).

59. Schachtrup, C. et al. Fibrinogen triggers astrocyte scar formation by promoting the availability of active TGF-beta after vascular damage. J. Neurosci. 30, 5843-5854 (2010).

60. Akassoglou, K., Yu, W. M., Akpinar, P. \& Strickland, S. Fibrin inhibits peripheral nerve remyelination by regulating Schwann cell differentiation. Neuron 33, 861-875 (2002).

61. Hacker, H. et al. Specificity in Toll-like receptor signalling through distinct effector functions of TRAF3 and TRAF6. Nature 439, 204-207 (2006).
62. Lam, C. K., Yoo, T., Hiner, B., Liu, Z. Q. \& Grutzendler, J. Embolus extravasation is an alternative mechanism for cerebral microvascular recanalization. Nature 465, 478-U101 (2010).

63. Gentleman, R. C. et al. Bioconductor: open software development for computational biology and bioinformatics. Genome Biol. 5, R80 (2004).

64. Benjamini, Y. \& Hochberg, Y. Controlling the false discovery rate-a practical and powerful approach to multiple testing. J. R. Stat. Soc. Ser B Methodol. 57, 289-300 (1995).

\section{Acknowledgements}

We thank Noah Saederup and Eric M. Verdin for providing us with $R A G 2^{-1-} \gamma c^{-1-}$ and OT-II mice, respectively. Expression vectors for recombinant fibrinogen were kindly provided by Lundbeck. We thank Athena Soulika for discussions and sharing myelin removal protocols, Dimitrios Davalos for critical reading of the manuscript, Matthew Helmrick and Collin Spencer for expert technical assistance. We thank Robert Nelson and Jeff Stavenhagen for discussions. This publication was made possible with the help from the University of California San Francisco-Gladstone Institute of Virology and Immunology Center for AIDS Research (P30 AI027763) and the Mouse Pathology Core of the UCSF Helen Diller Family Comprehensive Cancer Center (CA082103). S.S.Z. received support from the NIH (R01 AI073737 and R01 NS063008), the NMSS (RG4768, RG5179 and RG5180), the Guthy Jackson Charitable Foundation and Maisin Foundation, M.A.P from the Pediatric Scientist Development Program fellowship, J.L.D from the NIH/NHLBI grant HL096126 and I.F.C. from the NIH/NHLBI grant HL102475. This work was supported by the National Multiple Sclerosis Society (NMSS) Postdoctoral Fellowship and the American Heart Association Fellowship to J.K.R., the Howard Hughes Medical Institute Medical Research Fellowship to S.G.M and by the NMSS RG4985 and NIH/NINDS R01 NS052189 grants to K.A.

\section{Author contributions}

J.K.R. designed experiments, performed in vitro and in vivo studies and analyzed data; M.A.P. performed histological analysis; S.G.M. performed quantitative RT-PCR; K.B. analysed data and assisted with statistics and manuscript preparation; A.M.F. isolated primary microglia for microarray analysis; J.P.C., P.E.R.C. and M.R.M. performed histology and image analysis; E.V. produced recombinant fibrinogen; C.B. generated mouse lines and performed EAE; T.P. performed fluorescence-activated cell sorting analysis; I.F.C. generated the $C c r 2^{R F P /+}$ mice; H.L. designed experiments, performed data analysis and neuropathology, and edited the manuscript. J.L.D. provided fibrinogen mutant mice, isolated plasma, designed experiments and edited the manuscript; S.S.Z. designed T cell experiments analyzed, and interpreted data and edited the manuscript; S.S.Z. and K.A. jointly supervised the $\mathrm{T}$ cell experiments; K.A. conceived the project, designed the study, analyzed and interpreted data. K.A. and J.K.R. wrote the manuscript with input from all authors.

\section{Additional information}

Supplementary Information accompanies this paper at http://www.nature.com/ naturecommunications

Competing financial interests: The authors declare no competing financial interests

Reprints and permission information is available online at http://npg.nature.com/ reprintsandpermissions/

How to cite this article: Ryu, J. K. et al. Blood coagulation protein fibrinogen promotes autoimmunity and demyelination via chemokine release and antigen presentation. Nat. Commun. 6:8164 doi: 10.1038/ncomms9164 (2015).

This work is licensed under a Creative Commons Attribution 4.0 International License. The images or other third party material in this article are included in the article's Creative Commons license, unless indicated otherwise in the credit line; if the material is not included under the Creative Commons license, users will need to obtain permission from the license holder to reproduce the material To view a copy of this license, visit http://creativecommons.org/licenses/by/4.0/ 